\title{
Reactions of $\mathrm{NO}_{3}$ with aromatic aldehydes: gas-phase kinetics and insights into the mechanism of the reaction
}

\author{
Yangang Ren ${ }^{1}$, Li Zhou ${ }^{1, a}$, Abdelwahid Mellouki ${ }^{1,2}$, Véronique Daële ${ }^{1}$, Mahmoud Idir ${ }^{1}$, Steven S. Brown ${ }^{3,4}$, \\ Branko Ruscic ${ }^{5}$, Robert S. Paton ${ }^{6}$, Max R. McGillen ${ }^{1}$, and A. R. Ravishankara ${ }^{1,6,7,8}$ \\ ${ }^{1}$ Institut de Combustion Aèrothermique, Réactivité et Environnement, Centre National de la Recherche Scientifique \\ (ICARE-CNRS), Observatoire des Sciences de l'Univers en reìgion Centre (OSUC), CS 50060, \\ 45071 CEDEX02 Orléans, France \\ ${ }^{2}$ Environment Research Institute, School of Environmental Science and Engineering, Shandong University, \\ Qingdao 266237, China \\ ${ }^{3}$ NOAA, Chemical Sciences Laboratory, Boulder, CO, USA \\ ${ }^{4}$ Department of Chemistry, University of Colorado, Boulder, CO, USA \\ ${ }^{5}$ Chemical Sciences and Engineering Division, Argonne National Laboratory, Lemont, IL 60439, USA \\ ${ }^{6}$ Department of Chemistry, Colorado State University, Fort Collins, CO, USA \\ ${ }^{7}$ Department of Atmospheric Science, Colorado State University, Fort Collins, CO, USA \\ ${ }^{8}$ Le Studium Institute for Advanced Studies, Orléans, France \\ apresent address: College of Architecture and Environment, Sichuan University, Chengdu 610065, China
}

Correspondence: Abdelwahid Mellouki (mellouki@cnrs-orleans.fr) and A. R. Ravishankara

(a.r.ravishankara@colostate.edu)

Received: 16 March 2021 - Discussion started: 22 April 2021

Revised: 14 July 2021 - Accepted: 15 July 2021 - Published: 10 September 2021

\begin{abstract}
Rate coefficients for the reaction of $\mathrm{NO}_{3}$ radicals with a series of aromatic aldehydes were measured in a $7300 \mathrm{~L}$ simulation chamber at ambient temperature and pressure by relative and absolute methods. The rate coefficients for benzaldehyde (BA), ortho-tolualdehyde (O-TA), meta-tolualdehyde (M-TA), para-tolualdehyde (P-TA), 2,4-dimethyl benzaldehyde (2,4-DMBA), 2,5-dimethyl benzaldehyde (2,5-DMBA) and 3,5-dimethyl benzaldehyde $\left(3,5\right.$-DMBA) were $k_{1}=2.6 \pm 0.3, \quad k_{2}=8.7 \pm 0.8$, $k_{3}=4.9 \pm 0.5, \quad k_{4}=4.9 \pm 0.4, \quad k_{5}=15.1 \pm 1.3$, $k_{6}=12.8 \pm 1.2$ and $k_{7}=6.2 \pm 0.6$, respectively, in the units of $10^{-15} \mathrm{~cm}^{3}$ molec. ${ }^{-1} \mathrm{~s}^{-1}$ at $298 \pm 2 \mathrm{~K}$. The rate coefficient $k_{13}$ for the reaction of the $\mathrm{NO}_{3}$ radical with deuterated benzaldehyde (benzaldehyde- $\mathrm{d}_{1}$ ) was found to be half that of $k_{1}$. The end product of the reaction in an excess of $\mathrm{NO}_{2}$ was measured to be $\mathrm{C}_{6} \mathrm{H}_{5} \mathrm{C}(\mathrm{O}) \mathrm{O}_{2} \mathrm{NO}_{2}$. Theoretical calculations of aldehydic bond energies and reaction pathways indicate that the $\mathrm{NO}_{3}$ radical reacts primarily with aromatic aldehydes through the abstraction of
\end{abstract}

an aldehydic hydrogen atom. The atmospheric implications of the measured rate coefficients are briefly discussed.

\section{Introduction}

Aromatic aldehydes are a family of organic compounds emitted into the atmosphere from anthropogenic and pyrogenic sources. For example, benzaldehyde (BA) has been detected in the incomplete combustion of fuels (Legreid et al., 2007). Methylated benzaldehydes (ortho-, meta-, paratolualdehydes) are present in wood smoke and biomass burning plumes (Koss et al., 2018). Benzaldehyde also has extensive industrial usage in perfume, soap, food and drink production, and as a solvent for oils and resins (OECD, 2002). Benzaldehyde and ortho-, meta- and para-tolualdehyde could also be formed from the atmospheric degradation of aromatic hydrocarbons, although their yields in the atmosphere are expected to be small (Calvert et al., 2002; Obermeyer et al., 2009). 
It is known that the tropospheric removal of aromatic aldehydes occurs through photolysis (Clifford et al., 2011) and their reactions with the $\mathrm{OH}$ radical. During daytime, photolysis and reaction with $\mathrm{OH}$ dominate the atmospheric loss of the aromatic aldehydes. (We assume that the aromatic aldehydes photodissociate akin to aliphatic aldehydes). Yet, oxidation of aromatic aldehydes via their reaction with the nitrate radical, $\mathrm{NO}_{3}$, may be important in $\mathrm{NO}_{x}$-rich locations at night since both the aromatic aldehydes and the nitrate radical can arise from anthropogenic emissions and pyrogenic sources. To the best of our knowledge, there are no studies that have measured the formation of secondary organic aerosol (SOA) from the title reaction in either a chamber or in the atmosphere. One could suspect that aromatic aldehydes may be degraded at night with consequences for ozone and SOA formation. The reactions of aromatic aldehydes with $\mathrm{NO}_{3}$ likely lead to acyl peroxy nitrates (APNs, often referred to as PANs) in $\mathrm{NO}_{x}$-rich regions with characteristically high $\mathrm{NO}_{3}$ abundances. The APNs would then transport nitrogen oxides and the aromatic moieties from polluted to cleaner parts of the globe (Wayne, 2000) with consequences for ozone production and particle formation away from the polluted regions. Therefore, quantifying the kinetics and understanding the mechanism of the reaction of $\mathrm{NO}_{3}$ with aromatic aldehydes are needed.

In this study, the rate coefficients $k_{1}-k_{7}$ at $298 \mathrm{~K}$ for the reactions of the $\mathrm{NO}_{3}$ radical with the following seven aromatic aldehydes were measured.

benzaldehyde $(\mathrm{BA})+\mathrm{NO}_{3} \rightarrow$ products; $k_{1}$

ortho-tolualdehyde $(\mathrm{O}-\mathrm{TA})+\mathrm{NO}_{3} \rightarrow$ products; $k_{2}$

meta-tolualdehyde (M-TA) $+\mathrm{NO}_{3} \rightarrow$ products; $k_{3}$

para-tolualdehyde $(\mathrm{P}-\mathrm{TA})+\mathrm{NO}_{3} \rightarrow$ products; $k_{4}$

2, 4-dimethyl benzaldehyde (2,4-DMBA) $+\mathrm{NO}_{3}$

$\rightarrow$ products; $k_{5}$

2, 5-dimethyl benzaldehyde (2,5-DMBA) $+\mathrm{NO}_{3}$

$\rightarrow$ products; $k_{6}$

3, 5-dimethyl benzaldehyde (3,5-DMBA) $+\mathrm{NO}_{3}$

$\rightarrow$ products; $k_{7}$

The rate coefficient for Reaction (R1) has been previously reported by Carter et al. (1981), Atkinson et al. (1991), Clifford et al. (2005) and Bossmeyer et al. (2006). The rate coefficients for Reactions (R2)-(R4) were reported only by Clifford et al. (2005). There are no previous reports on $k_{5}-k_{7}$ to the best of our knowledge. The results from earlier studies are compared with our data in the section "Results and discussion".

We report the rate coefficients at $298 \mathrm{~K}$ for the above reactions, and we have determined the stable products formed in Reaction (R1). We have also attempted to elucidate the mechanism of these reactions via studies of isotopic substi- tution, quantum chemistry calculations and an examination of the linear free-energy relationship.

\section{Experimental setup and procedures}

The kinetics and products were studied in a $7300 \mathrm{~L}$ indoor simulation chamber described in detail previously (Zhou et al., 2017); therefore, it is described only briefly here. The chamber was made of Teflon foil. Two Teflon fans located inside the chamber rapidly mixed the contents of the chamber within about $30 \mathrm{~s}$. Purified air was used as a bath gas to flush the chamber clean between experiments. Upon flushing, the abundances of $\mathrm{NO}_{2}$ and $\mathrm{O}_{3}$ were less than 50 pptv (the detection limit of our instruments). A proton transfer reaction time-of-flight mass spectrometer (PTR-ToF-MS) and a Fourier transform infrared spectrometer (FTIR, Nicolet 5700) coupled to a White-type multipass cell (143 m optical path length) were employed to monitor the organic compounds in the chamber. The white cell was located within the chamber. An inlet situated in the center of the chamber fed the PTR-ToF-MS. The masses in PTR-ToF-MS and IR bands in the FTIR used to measure the aldehydes are listed in the Supplement (Table S1). The PTR-ToF-MS and/or FTIR signals were measured by expanding a known mass of liquid aldehyde into the chamber to determine hydrocarbons concentrations. Calibration plots for the quantification of the aromatic aldehydes and the reference gases were constructed using these measurements. They are shown in Fig. S1 in the Supplement. The concentrations of $\mathrm{NO}_{3}$ and $\mathrm{N}_{2} \mathrm{O}_{5}$ were determined using a cavity ring-down spectrometer (CRDS). The $\mathrm{NO}_{3}$ radical was detected using its strong $662 \mathrm{~nm}$ absorption. The sum of $\mathrm{NO}_{3}$ and $\mathrm{N}_{2} \mathrm{O}_{5}$ was detected simultaneously by thermally dissociating $\mathrm{N}_{2} \mathrm{O}_{5}$ in a second channel. The time resolution of CRDS was $1 \mathrm{~s}$, and the detection limit for $\mathrm{NO}_{3}$ and $\mathrm{N}_{2} \mathrm{O}_{5}$ was approximately $0.5 \mathrm{pptv}$ $\left(1.23 \times 10^{7}\right.$ molec. $\mathrm{cm}^{-3}$ at atmospheric pressure $)$ for a $5 \mathrm{~s}$ integration (Brown et al., 2002; Dubé et al., 2006). $\mathrm{NO}_{3}$ radicals were generated from the thermal decomposition of $\mathrm{N}_{2} \mathrm{O}_{5}$ in the chamber.

\subsection{Rate coefficient measurements}

Relative method. The temporal profiles of a reference compound and the aromatic aldehyde of interest were monitored simultaneously using the PTR-ToF-MS and/or FTIR in the presence of the $\mathrm{NO}_{3}$ radical.

$$
\begin{aligned}
& \mathrm{NO}_{3}+\text { aromatic aldehydes } \rightarrow \text { products; } k_{1-7} \\
& \mathrm{NO}_{3}+\text { references } \rightarrow \text { products; } k_{\text {ref }}
\end{aligned}
$$

We accounted for the dilution of the chamber necessitated by the addition of air to keep the pressure constant while we continually withdrew the chamber's contents for analysis. Similarly, we also accounted for the depletion of the hydrocarbons due to loss to the walls. The two processes together 
are represented as a first-order loss process with a rate coefficient $k_{d}$.

aromatic aldehydes/references $\rightarrow$ wall loss/dilution; $k_{d}$

Above, $k_{1-7}$ and $k_{\text {ref }}$ are the rate coefficient for the reaction of $\mathrm{NO}_{3}$ with studied aromatic aldehydes (BA, O-TA, MTA, P-TA, 2,4-DMBA, 2,5-DMBA and 3,5-DMBA) and the reference compound (methyl methacrylate, MMA), respectively. The dilution rate coefficient was measured by adding a small amount of unreactive $\mathrm{SF}_{6}$ into the chamber and monitoring its temporal decay. We quantified the rate coefficient (ranging from $5.5 \times 10^{-7}$ to $1.6 \times 10^{-6} \mathrm{~s}^{-1}$ ) for the removal of the aldehydes and reference compound due to loss on the walls by monitoring their decay in the absence of the $\mathrm{NO}_{3}$ reactant.

The typical experimental procedure for relative rate measurements consisted of a sequence of three steps: (1) $\mathrm{SF}_{6}$ was added at the beginning of the experiment and monitored to measure the dilution rate. During this time, as noted above, air was continually added to make up for the loss due to the withdrawal for analysis. (2) VOCs (volatile organic compounds - aromatic aldehydes, reference compounds) were introduced into the chamber and monitored for roughly $30 \mathrm{~min}$ to obtain $k_{d}$. (3) $\mathrm{N}_{2} \mathrm{O}_{5}$ was then continually introduced to the chamber using pure air as a carrier gas, and the consumption of VOCs was monitored using PTR-ToF-MS for 1-2 h. The typical initial VOC concentrations were $(0.9-$ $4.5) \times 10^{12}$ molec. $\mathrm{cm}^{-3}$ (Table S2). Typical $\mathrm{NO}_{3}$ concentrations were $(0.25-2.5) \times 10^{9}$ molec. $\mathrm{cm}^{-3}$.

Assuming that the aromatic aldehydes and reference compounds were lost by reaction with the $\mathrm{NO}_{3}$ radical and dilution and/or loss to the walls, it can be shown that

$\ln \left(\frac{[\mathrm{aro}]_{0}}{[\operatorname{aro}]_{t}}\right)-k_{d} \times t=\left(\frac{k_{1-7 \_\mathrm{RR}}}{k_{\mathrm{ref}}}\right) \times\left[\ln \left(\frac{[\mathrm{ref}]_{0}}{[\mathrm{ref}]_{t}}\right)-k_{d} \times t\right]$,

where $[\operatorname{aro}]_{0}$ and $[\operatorname{aro}]_{t}$ as well as $[\mathrm{ref}]_{t}$ and $[\mathrm{ref}]_{0}$ are the corresponding concentrations of aromatic aldehydes and the reference compound at the initial time and time $t$, respectively. According to Eq. (I), plots of $\left\{\ln \left(\frac{[\operatorname{aro}]_{0}}{[\operatorname{aro}]_{t}}\right)-k_{d} \times t\right\}$ against $\left\{\ln \left(\frac{[\mathrm{ref}]_{0}}{[\mathrm{ref}]_{t}}\right)-k_{d} \times t\right\}$ are straight lines of slope equal to $k_{1-7} / k_{\text {ref }}$, with zero intercepts.

Absolute method. Experiments were conducted in the same $7300 \mathrm{~L}$ simulation chamber described in the previous section. The temporal profiles of $\mathrm{NO}_{3}$ and $\mathrm{N}_{2} \mathrm{O}_{5}$ were measured using CRDS in an excess of each aromatic aldehyde (Zhou et al., 2017). They were simultaneously fit to a reaction scheme (see below) to extract the reaction rate coefficient as described by Zhou et al. (2017). The typical experimental procedure consisted of the following steps: (1) $\mathrm{N}_{2} \mathrm{O}_{5}$ was introduced with pure air into the chamber, and the temporal profiles of $\mathrm{NO}_{3}$ and $\mathrm{N}_{2} \mathrm{O}_{5}$ concentrations were measured to determine the rate coefficient for loss of $\mathrm{NO}_{3}$ and $\mathrm{N}_{2} \mathrm{O}_{5}$ to the walls, reactions with impurities and dilution. (2) The aromatic aldehyde of interest was introduced while continually measuring the temporal profiles of $\mathrm{NO}_{3}$ and $\mathrm{N}_{2} \mathrm{O}_{5}$. (3) $\mathrm{SF}_{6}$ was introduced to determine the dilution rate when needed.

A box model was used to integrate Reactions (R1)-(R11) to obtain the rate coefficients of $\mathrm{NO}_{3}$ radical reaction with aromatic aldehydes. The obtained temporal profiles of $\mathrm{NO}_{3}$ and $\mathrm{N}_{2} \mathrm{O}_{5}$ concentrations were fit to the observed profiles using a nonlinear least-squares algorithm.

$\mathrm{NO}_{3}+\mathrm{NO}_{2} \rightarrow \mathrm{N}_{2} \mathrm{O}_{5} ; k_{8}$
$\mathrm{~N}_{2} \mathrm{O}_{5} \rightarrow \mathrm{NO}_{3}+\mathrm{NO}_{2} ; k_{9}$
$\mathrm{NO}_{3} \rightarrow$ wall loss; $k_{10}$
$\mathrm{~N}_{2} \mathrm{O}_{5} \rightarrow$ wall loss; $k_{11}$
$\mathrm{NO}_{3}+$ aromatic aldehydes $\rightarrow$ products; $k_{1-7}$

In the algorithm, the sum of squares and the difference between calculated and measured values of both $\mathrm{NO}_{3}$ and $\mathrm{N}_{2} \mathrm{O}_{5}$ were minimized while varying the input parameters. In the absence of the aldehydes, the input parameter was just $k_{d}$. The value of $k_{d}$ obtained was then held constant when subsequently fitting the second set of temporal profiles where the rate coefficient for Reactions (R1)-(R7) was varied. The other input parameters included the measured initial concentration of $\mathrm{NO}_{3}\left(\left[\mathrm{NO}_{3}\right]_{0}\right), \mathrm{N}_{2} \mathrm{O}_{5}\left(\left[\mathrm{~N}_{2} \mathrm{O}_{5}\right]_{0}\right)$ and the initial aromatic aldehydes ([aro $\left.]_{0}\right)$ as well as the temperaturedependent values of $k_{8}$ and $k_{9}$ (to define the equilibrium constant $-K_{\text {eq }}$ ). We used the equilibrium constant for the reaction $\mathrm{NO}_{3}+\mathrm{NO}_{2} \rightleftharpoons \mathrm{N}_{2} \mathrm{O}_{5}$ recommended by Burkholder et al. (2015). The $\mathrm{NO}_{2}$ concentration was calculated through the equilibrium constant and measured concentrations of $\mathrm{NO}_{3}$ and $\mathrm{N}_{2} \mathrm{O}_{5}$ throughout the course of the reactions, i.e., $\left[\mathrm{NO}_{2}\right]=\left[\mathrm{N}_{2} \mathrm{O}_{5}\right] /\left(\left[\mathrm{NO}_{3}\right] \times K_{\mathrm{eq}}\right)$, and used in the fits. Such calculated temporal profiles of $\mathrm{NO}_{3}$ and $\mathrm{N}_{2} \mathrm{O}_{5}$ were fit to the measured temporal profiles at various concentrations of the aldehydes. As shown in Table S3, the concentration of aromatic aldehyde was always 50-1500 times higher than that of $\mathrm{NO}_{3}$ in the chamber at all times. Thus, $\mathrm{NO}_{3}$ loss was essentially first order in its concentration.

\subsection{Chemicals}

The aromatic aldehydes were purchased from SigmaAldrich. The stated purities of these chemicals were as follows: benzaldehyde ( $\geq 99.5 \%)$, O-TA (97\%), M-TA (97\%), P-TA ( $\geq 97 \%), 2,4$-DMBA ( $\geq 90 \%), 2,5$-DMBA $(99 \%)$ and 3,5-DMBA (97\%). Methyl methacrylate was bought from TCI. The chemical purity of benzaldehyde- $\alpha$-d 1 was $99 \%$, while its isotopic purity was $98 \%$. All the aldehydes (in liquid form) were further purified by repeated freeze-pumpthaw cycles before use. Substantial concentrations of reactive impurities were not detected in these samples based on the PTR-ToF-MS and FTIR measurements. A mixture of $\mathrm{NO}_{2}$ and $\mathrm{O}_{3}$ was flowed into a $1 \mathrm{~L}$ bulb to generate $\mathrm{N}_{2} \mathrm{O}_{5}$ through Reactions (R12) and (R8).

$\mathrm{NO}_{2}+\mathrm{O}_{3} \rightarrow \mathrm{NO}_{3}+\mathrm{O}_{2} ; k_{12}$ 
$\mathrm{NO}_{3}+\mathrm{NO}_{2} \rightarrow \mathrm{N}_{2} \mathrm{O}_{5} ; k_{8}$

The $\mathrm{N}_{2} \mathrm{O}_{5}$ crystals were collected in a cold trap $(190 \mathrm{~K})$ and purified by trap-to-trap distillation in a mixture of $\mathrm{O}_{2}$ and $\mathrm{O}_{3} \cdot \mathrm{N}_{2} \mathrm{O}_{5}$ was stored in a cold trap maintained at $190 \mathrm{~K}$.

\section{Results and discussion}

\subsection{Rate coefficient determination of $\mathrm{NO}_{3}$ reaction with a series of aromatic aldehydes}

In the study, we measured the rates coefficients $k_{1}-k_{7}$ using a relative method and an absolute method. They are outlined separately below for ease of presentation.

\subsubsection{Relative method}

Methyl methacrylate, MMA, was used as the reference compound in this work because the rate coefficient at $298 \mathrm{~K}$ for its reaction with the $\mathrm{NO}_{3}$ radical has been measured in the same chamber using the same method as used here (Zhou et al., 2017) to be $k_{\mathrm{MMA}}=(2.98 \pm 0.35) \times 10^{-15} \mathrm{~cm}^{3}$ molec. ${ }^{-1} \mathrm{~s}^{-1}$. We acknowledge that there are other recommendations that are slightly higher than the value we used. One can always renormalize the rate coefficient for any specific value. The experimental conditions and associated parameters are shown in Table $\mathrm{S} 2$.

Figure 1 shows plots of $\left\{\ln \left(\frac{\left[\operatorname{aro}_{0}\right.}{[\operatorname{aro}]_{t}}\right)-k_{d} \times t\right\}$ against $\left\{\ln \left(\frac{[\mathrm{ref}]_{0}}{[\operatorname{ref}]_{t}}\right)-k_{d} \times t\right\}$ for the seven aromatic aldehydes. Each plot is linear with an intercept of zero within the uncertainties. The $k_{d} \times t$ term is relatively small $(3.6 \%-7.6 \%)$ compared to the ratio $\left\{\frac{k_{d} \times t}{\ln \left(\frac{[\mathrm{aro}]_{0}}{[\operatorname{arr}]_{t}}\right) \text { or } \ln \left(\frac{[\mathrm{ref}]_{0}}{[\mathrm{ref}]_{t}}\right)}\right\}$, and slight variations in its value do not affect the accuracy of the measured rate coefficients. Figure 1 also shows that the measured values of the rate coefficient ratios are reproducible. The ratios of rate coefficients, $\frac{k_{1,7}}{k_{\text {ref }}}$, were calculated from these plots using the algorithm of Brauers and Finlayson-Pitts (1997), which takes into account errors in both the abscissa and ordinate. These errors were estimated from the uncertainty of the concentration calculated from the calibration plots generated before the kinetics runs. The noted errors for $\frac{k_{1,7}}{k_{\mathrm{ref}}}$ are twice the standard deviation in the least-squares fits multiplied by a factor to account for the limited number of measurements using the Student's $t$ distribution.

The relative rate coefficients of the studied aromatic aldehydes, termed $k_{\mathrm{RR}}$, are shown in Table S2. The estimated uncertainties for $k_{\mathrm{RR}}$ were the sum of the precision of our measurements (noted above) and the quoted uncertainties in the rate coefficient for the reference reaction according to the expression

$$
\sigma\left(k_{\mathrm{RR}}\right)=\frac{k}{k_{\mathrm{ref}}} \times k_{\mathrm{ref}} \sqrt{\left[\frac{\sigma_{k_{\mathrm{ref}}}}{k_{\mathrm{ref}}}\right]^{2}+\left[\frac{\mathrm{error}}{\frac{k}{k_{\mathrm{ref}}}}\right]^{2}} .
$$

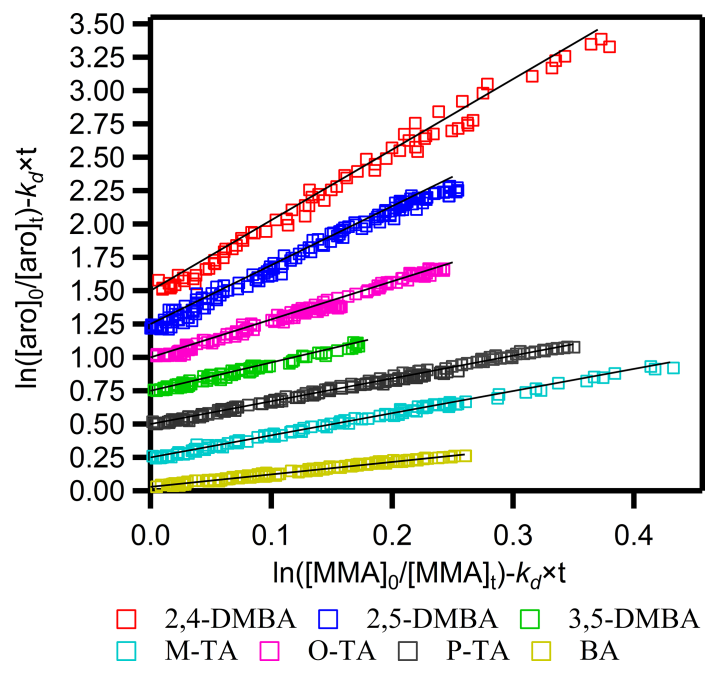

Figure 1. Plots of relative kinetic data obtained from the reaction of aromatic aldehydes (aro) with the $\mathrm{NO}_{3}$ radical using methyl methacrylate (MMA) as the reference. M-TA, P-TA, 3,5-DMBA, O-TA, 2,5-DMBA and 2,4-DMBA were shifted 0.25, 0.5, 0.75, 1.0, 1.25 and 1.5 , respectively, for clarity.

\subsubsection{Absolute method}

The method used to analyze the temporal profiles of $\mathrm{NO}_{3}$ and $\mathrm{N}_{2} \mathrm{O}_{5}$ to obtain $k_{1}-k_{7}$ has been described by Zhou et al. $(2017,2019)$. Figure 2 shows an example of the temporal profiles of $\mathrm{NO}_{3}$ and $\mathrm{N}_{2} \mathrm{O}_{5}$ for Reaction (R1) from which the rate coefficient $k_{1}$ was derived. Similar analyses yielded $k_{2}-$ $k_{7}$ (Figs. S2-S7).

Figure 2a shows the temporal profile of $\mathrm{NO}_{3}$ and $\mathrm{N}_{2} \mathrm{O}_{5}$ concentrations plotted on a logarithmic scale. The concentrations decrease exponentially (the lines are linear in the $\log$ space), and the decay rates are lower in the absence of the reactant aldehyde than in its presence. The rate coefficients for the loss of $\mathrm{NO}_{3}$ and $\mathrm{N}_{2} \mathrm{O}_{5}$ to the walls and dilution, $k_{10}$ and $k_{11}$, were determined to be in the ranges (3.77.1) $\times 10^{-3} \mathrm{~s}^{-1}$ and (3.2-12.0) $\times 10^{-4} \mathrm{~s}^{-1}$, respectively. As Zhou et al. (2017), we cannot merely take the slopes of decay of $\mathrm{NO}_{3}$ with time to calculate the rate coefficients $k_{1}-k_{7}$ since $\mathrm{NO}_{3}$ and $\mathrm{N}_{2} \mathrm{O}_{5}$ are coupled through their equilibrium. The equilibration is maintained throughout the course of Reactions (R1)-(R7). To account for this situation, we fit the profiles of both $\mathrm{NO}_{3}$ and $\mathrm{N}_{2} \mathrm{O}_{5}$ to a reaction scheme, as described previously.

Figure 2 panels (b) and (c) show the $\mathrm{NO}_{3}$ and $\mathrm{N}_{2} \mathrm{O}_{5}$ temporal profiles on a linear scale in the absence and the presence of the reactant aldehyde. The two panels also show the fits of the data to the mechanism that included only Reactions (R1)-(R11). The fits are acceptable but with larger variations at longer reaction times. We have to consider the contributions to $\mathrm{NO}_{3}$ and $\mathrm{N}_{2} \mathrm{O}_{5}$ losses due to the reactions of $\mathrm{NO}_{3}$ with the products of Reactions (R1)-(R7). Values of the rate coefficients derived from such fits included all the 
potential reactions that can contribute to the removal of $\mathrm{NO}_{3}$, and they are shown in the Supplement (Table S4). When the secondary reactions with the products were included, the fits were better at the longer reaction times, and they are shown in panel (d) of Fig. 2. The residuals of the fits are shown at the bottoms of panels (c) and (d); they clearly show the improvement in the fits and the lack of a trend with reaction time. Larger deviations are to be expected in panel (c) at longer reaction times as the reaction products build up. The rate coefficients $k_{1}-k_{7}$ calculated using the reaction scheme shown in Table $\mathrm{S} 4$ are taken to be those measured by the direct method. As expected, the rate coefficients calculated by including the contributions of the secondary reactions were slightly less than those without the secondary reaction contributions (see Fig. S8). The differences were, on average, about $5 \%$.

The results of our measured values for $k_{1-7}$ are summarized in Table S3. The quoted errors of the rate coefficient from each experiment are at the $95 \%$ confidence level based on the precision of the fits; they were typically less than $7 \%$. The weighted averages of results from multiple experiments were calculated, and then the influence of the small number of measurements was accounted for by using a Student's $t$ distribution table. We added the estimated systematic uncertainties to the precision in quadrature, assuming that they are uncorrelated. Contributions to estimated systematic errors included the following: (1) the systematic errors of $-8 /+11 \%$ and $-9 /+12 \%$, respectively, in the measurements of $\mathrm{NO}_{3}$ and $\mathrm{N}_{2} \mathrm{O}_{5}$ (Zhou et al., 2019); (2) the uncertainty of around $10 \%$ in the rate coefficients used in the reaction schemes shown in Table S4; and (3) the estimated uncertainty of $7 \%$ in the concentration of aromatic aldehydes. This includes the uncertainties in the calibration and spectral analysis. All the noted uncertainties are at the $95 \%$ confidence level, assuming a Gaussian error distribution.

It is important to note that we need the absolute concentrations of $\mathrm{NO}_{3}$ and $\mathrm{N}_{2} \mathrm{O}_{5}$ even though the reaction was first order in $\mathrm{NO}_{3}$ due to the strong coupling between the concentrations of $\mathrm{NO}_{3}$ and $\mathrm{N}_{2} \mathrm{O}_{5}$ via an equilibrium. The presence of the aldehydes would influence the temporal profiles of both $\mathrm{N}_{2} \mathrm{O}_{5}$ and $\mathrm{NO}_{3}$. Here we are attributing the entire change to the reaction of $\mathrm{NO}_{3}$ with the aldehydes. The validity of this assumption is shown by the measured rate coefficients being independent of the ratio of $\left[\mathrm{NO}_{3}\right] /\left[\mathrm{N}_{2} \mathrm{O}_{5}\right]$. This ratio was changed simply by changing $\left[\mathrm{NO}_{2}\right]$, which shifts the equilibrium concentrations of $\mathrm{NO}_{3}$ and $\mathrm{N}_{2} \mathrm{O}_{5}$.

\subsubsection{Comparison of rate coefficients obtained from absolute and relative methods}

The rate coefficients for the reactions of $\mathrm{NO}_{3}$ with seven different aromatic aldehydes, $k_{1}-k_{7}$, measured using the absolute and relative methods are summarized in Table 1 . The rate coefficient values from the two methods are in good agree-
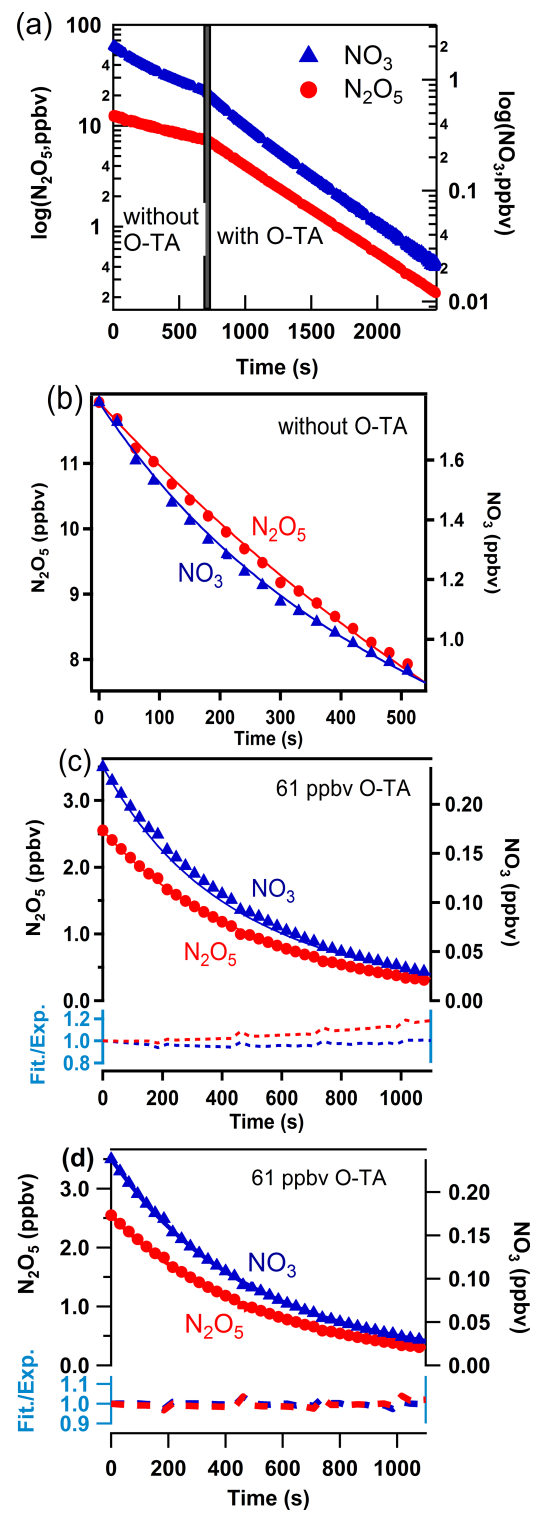

Figure 2. Observed (points) and simulated (lines) profiles of $\mathrm{N}_{2} \mathrm{O}_{5}$ (left axis) and $\mathrm{NO}_{3}$ (right axis) as a function of time. Mixing ratios of $o$-tolualdehyde are shown in each panel. Panel (a): the temporal profiles on a log scale. Panel (b): temporal profiles on a linear scale and the fits to the data as discussed in the text to determine the wall loss of $\mathrm{N}_{2} \mathrm{O}_{5}$ and $\mathrm{NO}_{3}$ during the experiment. Panel (c): fits of simulations not including the subsequent secondary reactions of $\mathrm{NO}_{3}$ with the products of the initial reaction. The dashed lines at the bottom show the ratio of simulated lines to measured data points (Fit./Exp.) for $\mathrm{NO}_{3}$ (blue) and $\mathrm{N}_{2} \mathrm{O}_{5}$ (red). Panel (d): fits of simulations including the subsequent secondary reactions of $\mathrm{NO}_{3}$ with the initial reaction products (shown in Table S4). The dashed lines at the bottom show the ratio of simulated lines to measured data points (Fit./Exp.) for $\mathrm{NO}_{3}$ (blue) and $\mathrm{N}_{2} \mathrm{O}_{5}$ (red). The improvements in the fits are clear in panel (d). 
ment with each other. The differences are less than $10 \%$, except for $k_{1}$, which differs by $18 \%$.

As shown in Table 2, the final rate coefficients of seven aromatic aldehydes reacting with the $\mathrm{NO}_{3}$ radical were derived from the weighted average of the absolute and the relative rate methods using the equation discussed above (Eqs. S2 and S3).

\subsubsection{Comparison with the literature for $\mathrm{NO}_{3}$ radical kinetics with aromatic aldehydes}

Table 2 summarizes the rate coefficients measured in this work with data from the literature for reactions of the $\mathrm{NO}_{3}$ radical with aromatic aldehyde, BA, O-TA, M-TA, P-TA, 2,4-DMBA, 2,5-DMBA and 3,5-DMBA. As shown in Table 2, the rate coefficient for BA has been reported by five studies. Three of them (Atkinson et al., 1984; Carter et al., 1981; Clifford et al., 2005) used the relative method with different reference compounds. Atkinson et al. (1991) corrected the values from their earlier report, and they are used for the comparison. Bossmeyer et al. (2006) measured both $\mathrm{NO}_{3}$ and BA using differential optical absorption spectroscopy (DOAS) in their chamber. They measured the loss of BA in a known (measured continuously) $\mathrm{NO}_{3}$ concentration and fitted BA's measured temporal profile to obtain $k_{1}$. Calvert et al. (2011) recommended $k_{7}$ to be $4.0 \times 10^{-15} \mathrm{~cm}^{3}$ molec. ${ }^{-1} \mathrm{~s}^{-1}$ with a $30 \%$ uncertainty based on these studies. However, our value from absolute and relative methods using methyl methacrylate as a reference reaction (its rate coefficient was determined using the absolute method in our previous study; Zhou et al., 2017) is in good agreement with Atkinson (1991) and Bossmeyer et al. (2006). Hence, we suggest that the weighted average based on these three studies, $2.6 \pm 0.3 \times 10^{-15} \mathrm{~cm}^{3}$ molec. $^{-1} \mathrm{~s}^{-1}$ at $298 \pm 2 \mathrm{~K}$, is a reliable value. The rate coefficients for ortho-, meta- and para-tolualdehyde have only been studied by Clifford et al. (2005), who reported them to be $(9.8 \pm 0.4),(9.5 \pm 0.4)$ and $(9.5 \pm 0.7) \times 10^{-15} \mathrm{~cm}^{3}$ molec. ${ }^{-1} \mathrm{~s}^{-1}$, respectively. In this work, $k_{1}-k_{7}$ were determined relative to MMA as the reference as well as using an absolute method to be $(8.5 \pm 1.0$ and $9.1 \pm 1.2),(5.1 \pm 0.6$ and $4.7 \pm 0.6)$ and $(5.0 \pm 0.6$ and $4.8 \pm 0.6) \times 10^{-15} \mathrm{~cm}^{3}$ molec. ${ }^{-1} \mathrm{~s}^{-1}$, respectively. This work agrees best with the value of Clifford et al. (2005) for orthotolualdehyde, but those of $k_{3}$ and $k_{4}$ are smaller than those of Clifford et al. (2005). The reasons for these discrepancies are unclear, but the excellent agreement $(<7 \%$ difference) between the two techniques presented here gives us confidence in our determinations. This work provides the first experimental determinations of the rate coefficients for $\mathrm{NO}_{3}$ reactions with 2,4-DMBA, 2,5-DMBA and 3,5-DMBA; the two complementary methods agree well. The recommended rate coefficients of the weighted average of the relative method and absolute method are shown in Table 2.

\subsection{Mechanisms of the reactions}

\subsubsection{Product investigation from the reaction of benzaldehyde with $\mathrm{NO}_{3}$}

The stable products formed in Reaction (R1) were investigated at $298 \pm 2 \mathrm{~K}$ and 760 Torr in the same $7300 \mathrm{~L}$ simulation chamber. Benzaldehyde at $0.9-1.4 \times 10^{13}$ molec. $\mathrm{cm}^{-3}$ (as shown in Table S5) was introduced into the chamber, and its removal was measured for $2 \mathrm{~h}$ to obtain the wall loss rate coefficient. Then, roughly $1.1 \times 10^{12}-1.5 \times 10^{14}$ molec. $\mathrm{cm}^{-3}$ of $\mathrm{N}_{2} \mathrm{O}_{5}$ was introduced. Stable products formed in the chamber were identified and quantified (when possible) using the PTR-ToF-MS and FTIR.

Two stable products, $\mathrm{C}_{6} \mathrm{H}_{5} \mathrm{C}(\mathrm{O}) \mathrm{O}_{2} \mathrm{NO}_{2}$ (benzaldehydePAN; BAPAN) and $\mathrm{C}_{6} \mathrm{H}_{5} \mathrm{ONO}_{2}$, were detected and measured. The former was detected using both PTR-ToF-MS $(m / z \quad 184.024$ and its fragment $m / z 105.034)$ and FTIR $\left(965-1005 \mathrm{~cm}^{-1}\right.$ centered at $\left.989 \mathrm{~cm}^{-1}\right)$ and the latter using only PTR-ToF-MS. Since we do not have a sample of BAPAN, we could not quantify the yield of this product using PTR-ToF-MS. However, Caralp et al. (1999) reported the IR band strengths for BAPAN. Using their reported band strength, we could quantify BAPAN to be $80 \pm 10 \%$ of the benzaldehyde that was removed via reaction; the quoted uncertainty is the precision in the fit at the $2 \sigma$ level. When we account for the uncertainties in the absorption cross sections of BAPAN reported by Caralp et al. (1999) ( 20\%), account for the uncertainties in the concentration of the initial benzaldehyde concentration $(\sim 10 \%)$ and add the precision of the measurements, we conclude that the yield of BAPAN is $80 \pm 22 \%$. We assume that the uncertainties are uncorrelated and hence added them in quadrature. The obtained BAPAN amounts are shown in Fig. 3 as a function of benzaldehyde consumption; the details are shown in Table $\mathrm{S} 5$ in the Supplement. We could not quantify $\mathrm{C}_{6} \mathrm{H}_{5} \mathrm{ONO}_{2}$ because of the lack of a standard. Assuming that the ionmolecule reaction rate coefficients for proton transfer to BAPAN and $\mathrm{C}_{6} \mathrm{H}_{5} \mathrm{ONO}_{2}$ are similar, we estimate that the yield of $\mathrm{C}_{6} \mathrm{H}_{5} \mathrm{ONO}_{2}$ is smaller than that of BAPAN. These two products are expected if the reaction proceeds via $\mathrm{H}$-atom abstraction and most of the peroxy radical reacts with $\mathrm{NO}_{2}$ (Platz et al., 1998), as denoted by Reaction (A).

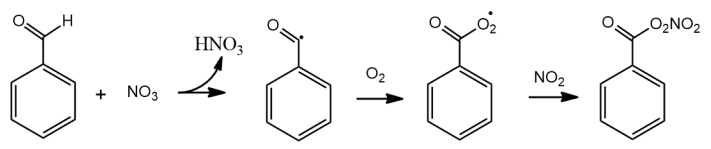


Table 1. Rate coefficients $k_{1}-k_{7}$ measured in the study using two different methods.

\begin{tabular}{|c|c|c|c|c|}
\hline \multirow[t]{2}{*}{$\begin{array}{l}\text { Aromatic } \\
\text { aldehydes }\end{array}$} & \multicolumn{2}{|c|}{$\begin{array}{c}\text { Rate coefficient } \\
\left(10^{-15} \mathrm{~cm}^{3} \text { molec. }^{-1} \mathrm{~s}^{-1}\right)\end{array}$} & \multirow[t]{2}{*}{$\begin{array}{r}\text { Ratio } \\
\left(k_{\mathrm{RR}} / k_{\mathrm{AR}}\right)\end{array}$} & \multirow[t]{2}{*}{$\left(10^{-15} \mathrm{~cm}^{3}\right.$ molec. $\left.{ }^{-1} \mathrm{~s}_{\text {final }}^{* 1}\right)$} \\
\hline & $k_{\mathrm{RR}}$ & $k_{\mathrm{AR}}$ & & \\
\hline BA & $2.8 \pm 0.4$ & $2.3 \pm 0.4$ & 1.18 & $2.5 \pm 0.3$ \\
\hline O-TA & $8.5 \pm 1.0$ & $9.1 \pm 1.2$ & 0.93 & $8.7 \pm 0.8$ \\
\hline M-TA & $5.1 \pm 0.6$ & $4.7 \pm 0.6$ & 1.07 & $4.9 \pm 0.5$ \\
\hline P-TA & $5.0 \pm 0.6$ & $4.8 \pm 0.6$ & 1.05 & $4.9 \pm 0.4$ \\
\hline 2,4-DMBA & $15.5 \pm 1.8$ & $14.6 \pm 2.0$ & 1.06 & $15.1 \pm 1.3$ \\
\hline 2,5-DMBA & $13.4 \pm 1.6$ & $12.2 \pm 1.7$ & 1.09 & $12.8 \pm 1.2$ \\
\hline 3,5-DMBA & $6.4 \pm 0.8$ & $6.1 \pm 0.8$ & 1.05 & $6.2 \pm 0.6$ \\
\hline
\end{tabular}

* Weighted average of these relative and absolute measurements as well as their error calculated using Eqs. (S2) and (S3).

Table 2. Experimental results of this study compared with those from the literature for the reactions of the $\mathrm{NO}_{3}$ radical with benzaldehyde (BA), $o$-tolualdehyde (O-TA), $m$-tolualdehyde (M-TA), $p$-tolualdehyde (P-TA), 2,4-dimethylbenzaldehyde (2,4-DMBA), 2,5dimethylbenzaldehyde (2,5-DMBA) and 3,5-dimethylbenzaldehyde (3,5-DMBA).

\begin{tabular}{|c|c|c|c|c|c|c|}
\hline VOC & $\left(\times 10^{-15} \mathrm{~cm}^{3} \text { molec }^{-1} \mathrm{~s}^{-1}\right)^{k}$ & $T(\mathrm{~K})$ & Technique & Reference compound & $\begin{array}{r}\text { Ref. } \\
\left(\times 10^{-15} \mathrm{~cm}^{3} \text { molec. }^{-1} \mathrm{~s}^{-1}\right)\end{array}$ & Ref. \\
\hline BA & $\begin{array}{r}<8 \\
1.1 \pm 0.3 \\
2.6 \pm 0.1 \\
4.2 \pm 0.2 \\
4.5 \pm 0.3 \\
2.2 \pm 0.6 \\
2.8 \pm 1.0 \\
2.3 \pm 0.4 \\
2.6 \pm 0.3^{\mathrm{a}}\end{array}$ & $\begin{array}{l}300 \pm 1 \\
296 \pm 2 \\
296 \pm 2 \\
295 \pm 2 \\
295 \pm 2 \\
301 \pm 3 \\
298 \pm 1 \\
298 \pm 1 \\
298 \pm 2\end{array}$ & $\begin{array}{l}\text { relative } \\
\text { relative } \\
\text { relative } \\
\text { relative } \\
\text { relative } \\
\text { absolute } \\
\text { relative } \\
\text { absolute }\end{array}$ & $\begin{array}{l}\text { propene } \\
\text { propene } \\
\text { propene } \\
\text { tetrahydrofuran } \\
n \text {-propyl ether } \\
\text { MMA }\end{array}$ & $\begin{array}{r}7.90 \\
4.07 \\
9.50 \\
4.90 \\
4.90 \\
\\
2.98 \pm 0.35\end{array}$ & $\begin{array}{l}\text { Carter et al. (1981) } \\
\text { Atkinson et al. (1984) } \\
\text { Atkinson et al. (1991) } \\
\text { Clifford et al. (2005) } \\
\text { Clifford et al. (2005) } \\
\text { Bossmeyer et al. (2006) } \\
\text { this work } \\
\text { this work } \\
\text { recommended }\end{array}$ \\
\hline O-TA & $\begin{array}{r}9.3 \pm 0.3 \\
10.3 \pm 0.4 \\
8.5 \pm 1.6 \\
9.1 \pm 1.3 \\
8.7 \pm 0.8^{\mathrm{b}}\end{array}$ & $\begin{array}{l}295 \pm 2 \\
295 \pm 2 \\
298 \pm 1 \\
298 \pm 1 \\
298 \pm 1\end{array}$ & $\begin{array}{l}\text { relative } \\
\text { relative } \\
\text { relative } \\
\text { absolute }\end{array}$ & $\begin{array}{l}\text { tetrahydrofuran } \\
n \text {-propyl ether } \\
\text { MMA }\end{array}$ & $\begin{array}{r}4.90 \\
4.90 \\
2.98 \pm 0.35\end{array}$ & $\begin{array}{l}\text { Clifford et al. (2005) } \\
\text { Clifford et al. (2005) } \\
\text { this work } \\
\text { this work } \\
\text { recommended }\end{array}$ \\
\hline M-TA & $\begin{array}{r}9.4 \pm 0.4 \\
9.6 \pm 0.4 \\
4.9 \pm 1.2 \\
4.6 \pm 0.7 \\
4.9 \pm 0.5^{b}\end{array}$ & $\begin{array}{l}295 \pm 2 \\
295 \pm 2 \\
298 \pm 1 \\
298 \pm 1\end{array}$ & $\begin{array}{l}\text { relative } \\
\text { relative } \\
\text { relative } \\
\text { absolute }\end{array}$ & $\begin{array}{l}\text { tetrahydrofuran } \\
n \text {-propyl ether } \\
\text { MMA }\end{array}$ & $\begin{array}{r}4.90 \\
4.90 \\
2.98 \pm 0.35\end{array}$ & $\begin{array}{l}\text { Clifford et al. (2005) } \\
\text { Clifford et al. (2005) } \\
\text { this work } \\
\text { this work } \\
\text { recommended }\end{array}$ \\
\hline P-TA & $\begin{array}{r}8.4 \pm 0.7 \\
10.2 \pm 0.4 \\
5.0 \pm 1.2 \\
4.8 \pm 0.7 \\
4.9 \pm 0.4^{b}\end{array}$ & $\begin{array}{l}295 \pm 2 \\
295 \pm 2 \\
297 \pm 1 \\
297 \pm 1\end{array}$ & $\begin{array}{l}\text { relative } \\
\text { relative } \\
\text { relative } \\
\text { absolute }\end{array}$ & $\begin{array}{l}\text { tetrahydrofuran } \\
n \text {-propyl ether } \\
\text { MMA }\end{array}$ & $\begin{array}{r}4.90 \\
4.90 \\
2.98 \pm 0.35\end{array}$ & $\begin{array}{l}\text { Clifford et al. (2005) } \\
\text { Clifford et al. (2005) } \\
\text { this work } \\
\text { this work } \\
\text { recommended }\end{array}$ \\
\hline 2,4-DMBA & $\begin{array}{r}15.8 \pm 2.2 \\
14.6 \pm 2.0 \\
15.1 \pm 1.3^{\mathrm{b}}\end{array}$ & $\begin{array}{l}297 \pm 1 \\
297 \pm 1\end{array}$ & $\begin{array}{l}\text { relative } \\
\text { absolute }\end{array}$ & MMA & $2.98 \pm 0.35$ & $\begin{array}{l}\text { this work } \\
\text { this work } \\
\text { recommended }\end{array}$ \\
\hline 2,5-DMBA & $\begin{array}{r}13.2 \pm 1.9 \\
12.2 \pm 1.7 \\
12.8 \pm 1.2^{b}\end{array}$ & $\begin{array}{l}297 \pm 1 \\
297 \pm 1\end{array}$ & $\begin{array}{l}\text { relative } \\
\text { absolute }\end{array}$ & MMA & $2.98 \pm 0.35$ & $\begin{array}{l}\text { this work } \\
\text { this work } \\
\text { recommended }\end{array}$ \\
\hline 3,5-DMBA & $\begin{array}{r}6.2 \pm 1.3 \\
6.1 \pm 0.9 \\
6.2 \pm 0.6^{b}\end{array}$ & $\begin{array}{l}297 \pm 1 \\
297 \pm 1\end{array}$ & $\begin{array}{l}\text { relative } \\
\text { absolute }\end{array}$ & MMA & $2.98 \pm 0.35$ & $\begin{array}{l}\text { this work } \\
\text { this work } \\
\text { recommended }\end{array}$ \\
\hline
\end{tabular}

${ }^{a}$ Weighted average of Atkinson (1991), Bossmeyer et al. (2006) and this work including results of the relative and absolute method. ${ }^{\text {b }}$ Values shown in Table 1. 


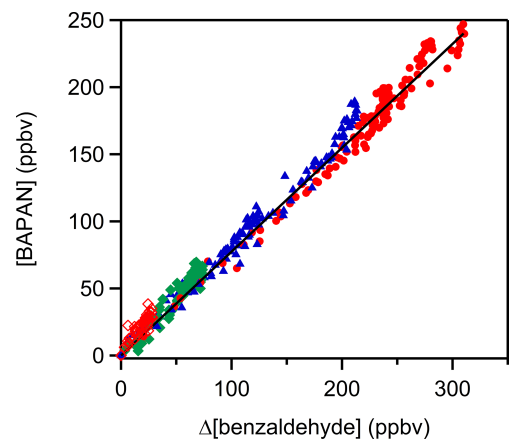

Figure 3. A plot of benzaldehyde $\mathrm{PAN}\left(\mathrm{C}_{6} \mathrm{H}_{5} \mathrm{C}(\mathrm{O}) \mathrm{O}_{2} \mathrm{NO}_{2}\right.$; $\mathrm{BA}-$ PAN) concentrations measured by FTIR as a function of depletion of benzaldehyde. The slope of the plot gives a yield of the BAPAN in the $\mathrm{NO}_{x}$-rich environment of roughly $80 \pm 22 \%$. Note: the different colors and markers represent repeated experiments with different initial $\mathrm{NO}_{2}$ concentrations. Red filled circles: $\left[\mathrm{NO}_{2}\right]_{0}=1.4-2.9 \times 10^{12}$ molec. $\mathrm{cm}^{-3}$ molec. $\mathrm{cm}^{-3}$, blue triangle: $\left.\left[\mathrm{NO}_{2}\right]_{0}\right]=\sim 2.8 \times 10^{13}$ molec. $\mathrm{cm}^{-3}$, green square: $\left[\mathrm{NO}_{2}\right]_{0}=\sim$ $1.4 \times 10^{14}$ molec. $\mathrm{cm}^{-3}$, red open diamond: $\left[\mathrm{NO}_{2}\right]_{0}=\sim 3.3 \times$ $10^{14}$ molec. $\mathrm{cm}^{-3}$.

A fraction of the peroxy radicals reacts with itself (or other peroxy radicals) to make phenoxy radicals, which ultimately leads to a nitrate, according to Reaction (B).
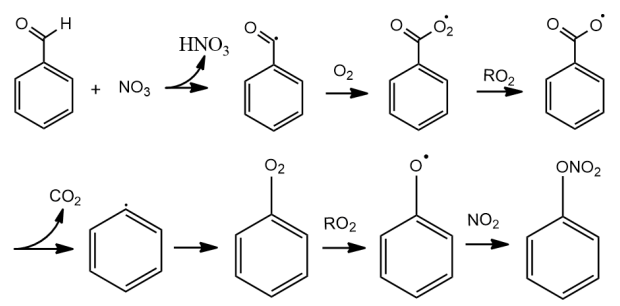

Unfortunately, we could not reduce the concentration of $\mathrm{NO}_{2}$ sufficiently to suppress Reaction (B) completely. A small fraction of the $\mathrm{C}_{6} \mathrm{H}_{5} \mathrm{C}(\mathrm{O}) \mathrm{O}_{2}$ would also react with $\mathrm{NO}_{3}$ but would still yield the $\mathrm{C}_{6} \mathrm{H}_{5} \mathrm{C}(\mathrm{O}) \mathrm{O}$ radicals. Also, any reactions of the phenyl radical with $\mathrm{NO}_{2}$ can be neglected because of the large abundance of $\mathrm{O}_{2}$ that will quickly convert it to the $\mathrm{C}_{6} \mathrm{H}_{5} \mathrm{O}_{2}$ radical. Numerical modeling of the reaction sequence shown in the Supplement (Table S4) suggests that the yield of BAPAN is more than $95 \%$ under our experimental conditions. Based on these results, we suggest the yield of BAPAN in our reaction system to be essentially 1 and that we detect the nitrate because of the high sensitivity for its detection in our PTR-ToF-MS.

\subsubsection{Kinetic isotope effect in the reaction}

To further examine the mechanism of $\mathrm{NO}_{3}$ reactions with the aromatic aldehydes, we measured the rate coefficient for the reaction of the $\mathrm{NO}_{3}$ radical with benzaldehyde- $\alpha$-d1 $\left(\mathrm{C}_{6} \mathrm{H}_{5} \mathrm{CDO}\right)$.

$\mathrm{C}_{6} \mathrm{H}_{5} \mathrm{C}(\mathrm{O}) \mathrm{D}+\mathrm{NO}_{3} \rightarrow$ products; $k_{13}$

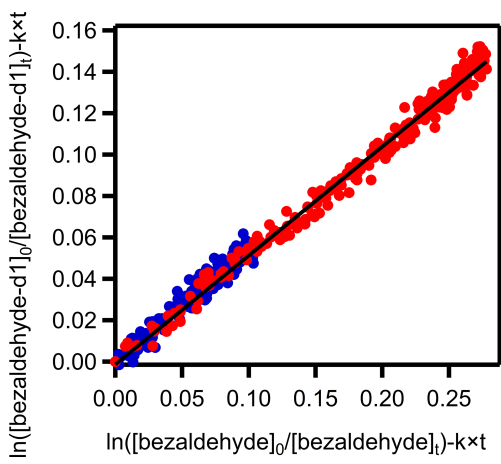

Figure 4. The plot of the logarithm (base e) of the ratio of the initial benzaldehyde-d 1 concentration to those at other reaction times against the logarithm (base e) of the ratio of the initial benzaldehyde concentration relative to those at different times. Both benzaldehyde and benzaldehyde-d1 were competing for the same pool of $\mathrm{NO}_{3}$ radicals. The slope of the plot is $0.53 \pm 0.01$. The red and blue circles represent two experiments with different concentrations of $\mathrm{NO}_{3}$ radicals.

As shown in Fig. $4, k_{13}$ is half that of $k_{1}-$ i.e., $k_{1} / k_{13}$ is 1.92. A factor of 2 decrease in the rate coefficient going from benzaldehyde to benzaldehyde- $\alpha$-d 1 is consistent with a primary kinetic isotope effect (KIE), suggesting that abstraction of the aldehydic $\mathrm{H}$ atom occurs in the rate-limiting step of this reaction pathway (see calculated KIE below).

\subsubsection{Reaction pathway}

Linear free-energy relationships comparing the reactivities of $\mathrm{OH}$ and $\mathrm{NO}_{3}$ with a series of organic compounds are shown in the Supplement (Fig. S9). Such correlations have been demonstrated in the past by Clifford et al. (2005). We have added our measured values of $k_{1}-k_{7}$ to the plot. This plot suggests that the linear free-energy relationship is consistent with $\mathrm{NO}_{3}$ radicals adding to the seven aromatic aldehydes studied here. Even the reaction of $\mathrm{OH}$ radicals with aliphatic aldehydes is known to proceed by forming a prereaction complex.

Figure 5 shows the rate coefficients for the reaction of the $\mathrm{NO}_{3}$ radical with the seven aldehydes studied here (also presented in Table 2), along with those with benzene and toluene $\left(<3 \times 10^{-17}\right.$ and $<6.6 \times 10^{-17} \mathrm{~cm}^{3}$ molec. $\left.{ }^{-1} \mathrm{~s}^{-1}\right)$ (Calvert et al., 2002). Benzene and toluene do not react with $\mathrm{NO}_{3}$ to measurable extents; such reactions may be expected if they proceeded via electrophilic addition. Since it is not sufficiently reactive to abstract an $\mathrm{H}$ atom from either the ring or the methyl group, the rate coefficient is very slow, if not zero. Therefore, the observed reaction rate coefficients suggest that the reaction proceeds via an $\mathrm{H}$-atom abstraction from the -CHO group (Clifford et al., 2005; Wayne et al., 1991). The rate coefficient for the reaction of $\mathrm{NO}_{3}$ with benzaldehyde, $(2.6 \pm 0.3) \times 10^{-15} \mathrm{~cm}^{3}$ molec. ${ }^{-1} \mathrm{~s}^{-1}$, is similar to that with acetaldehyde of $(2.7 \pm 0.5) \times 10^{-15} \mathrm{~cm}^{3}$ molec. ${ }^{-1} \mathrm{~s}^{-1}$, 
as shown in Fig. 5. The mechanism for the reaction of $\mathrm{NO}_{3}$ with acetaldehyde is believed to be $\mathrm{H}$-atom abstraction from the $-\mathrm{CHO}$ group after the formation of a pre-reaction complex.

As shown in Fig. 5 (also presented in Table 2), this work finds a higher rate coefficient for the reactions of $\mathrm{NO}_{3}$ with ortho-, meta- and para-tolualdehydes than that with benzaldehyde. This enhanced reactivity with ring substitution by electron-donating groups suggests an electrophilic role for $\mathrm{NO}_{3}$ in the reaction. Clifford et al. (2005) noted that the direct influence of the electron donation to the ring by the $\mathrm{CH}_{3}$ group is effectively canceled out by the electron-withdrawing effect of the - CHO group as an explanation for their measured rate coefficients being the same for all the tolualdehydes. The trends we observe for substituting methyl groups in the tolualdehydes and the demethylated aldehydes could suggest electrophilic addition. Of course, the initial addition has to lead to the abstraction of the aldehydic $\mathrm{H}$ atom, as shown by the products and the kinetic isotope effect. Alternatively, the reactivity trend could simply be due to the $\mathrm{C}-\mathrm{H}$ bond energy changes in the aldehydic group upon methyl substitution.

The $\mathrm{C}-\mathrm{H}$ bond dissociation enthalpies (BDEs) of benzaldehyde and the three tolualdehydes have been obtained from Active Thermochemical Tables (ATcT). As opposed to traditional sequential thermochemistry, ATcT obtains enthalpies of formation by constructing, statistically analyzing and solving a global thermochemical network (TN), which is formed by including experimental and theoretical determinations pertinent to the chemical species that are included in the network, as explained in more detail elsewhere (Ruscic et al., 2004, 2005).

The results presented here are based on the most current ATcT TN (ver. 1.122x), obtained by further expanding prior (Bross et al., 2019; Zaleski et al., 2021) versions (1.122r and $1.122 \mathrm{v}$ ) by including species of interest in the present study, as well as other ongoing investigations. The current $\mathrm{TN}$ incorporates $\sim 2350$ species, interconnected by $\sim 29000$ experimental and theoretical determinations.

Typically, the insertion of a new chemical species in the $\mathrm{TN}$ begins by linking the new species to the already existing species via a provisional skeleton of theoretical isodesmic reactions computed using a standard set of mid-level composite calculations carried out in-house and currently consisting of W1 (Martin and de Oliveira, 1999; Parthiban and Martin, 2001), CBS-APNO (Ochterski et al., 1996), G4 (Curtiss et al., 2007), G3X (Curtiss et al., 2000) and CBS-QB3 (Montgomery et al., 1999, 2000). This is subsequently complemented by experimental and theoretical determinations from the literature and, when possible, additional state-ofthe-art high-level composite calculations that can deliver sub-kJ mol ${ }^{-1}$ accuracies. As the number and accuracy of additional determinations grow, the dependence of the final result on the determinations spanning the initial skeleton diminishes and ultimately vanishes.
However, while the enthalpies of formation of gas-phase benzaldehyde and the three tolualdehydes are linked in the $\mathrm{TN}$ to their condensed phases, for which there are some thermochemically relevant experimental data in the literature, the reported BDEs rely heavily on the results of mid-level composite methods given the paucity of literature on experimental or theoretical data involving the benzoyl and toluyl radicals and the prohibitively high cost of state-of-the-art highlevel composite calculations for this size of species. Analogously, our attempts to expand the TN with dimethyl benzaldehydes and their related radicals were frustrated by a virtual absence of experimental and worthwhile theoretical data in the literature, combined with the high cost of theoretical calculations even using mid-level composite methods.

The ATcT BDEs of the aldehydic $\mathrm{C}-\mathrm{H}$ in benzaldehyde and the three tolualdehydes are given at 298.15 and $0 \mathrm{~K}$ in Table S6, together with the corresponding enthalpies of formation of the parents and the related radicals. While only the 298.15 K BDEs are discussed below, the corresponding $0 \mathrm{~K}$ BDEs (a.k.a. $\mathrm{D}_{0}$ values) are also given in the same table and are, as expected, approximately $6.3 \mathrm{~kJ} \mathrm{~mol}^{-1}($ or $\sim 2.5 \mathrm{RT})$ lower. The ATcT uncertainties provided in Table S6 correspond to $95 \%$ confidence intervals, following the standard in thermochemistry (Ruscic, 2014; Ruscic and Bross, 2019), and were obtained by using the full ATcT covariance matrix. Consequently, when the enthalpy of formation of the radical is highly correlated with that of the parent, as happens to be true in benzaldehyde and tolualdehydes, the uncertainty of the resulting $\mathrm{BDE}$ is perceptibly lower than the uncertainty that would be obtained by manually propagating the uncertainties of the individual enthalpies of formation in quadrature, since the latter summation assumes zero covariances.

The ATcT BDE of the aldehydic $\mathrm{C}-\mathrm{H}$ in benzaldehyde is $\mathrm{BDE}_{298}\left(\mathrm{C}_{6} \mathrm{H}_{5} \mathrm{C}(\mathrm{O})-\mathrm{H}\right)=380.10 \pm 0.84 \mathrm{~kJ} \mathrm{~mol}^{-1}$. This is noticeably higher (by $6.77 \pm 0.84 \mathrm{~kJ} \mathrm{~mol}^{-1}$ ) than the corresponding BDE of the prototypical aldehyde - acetaldehyde - for which the current version of the ATcT TN produces $\mathrm{BDE}_{298}\left(\mathrm{CH}_{3} \mathrm{C}(\mathrm{O})-\mathrm{H}\right)=373.37 \pm 0.29 \mathrm{~kJ} \mathrm{~mol}^{-1}$ (essentially unchanged from the web-accessible value in the earlier ATcT TN ver. 1.122p; Rusic and Bross, 2020).

Of particular relevance here is the fact that the aldehydic $\mathrm{C}-\mathrm{H}$ BDEs in meta- and paratolualdehyde, which are $\mathrm{BDE}_{298}\left(m-\mathrm{CH}_{3} \mathrm{C}_{6} \mathrm{H}_{4} \mathrm{C}(\mathrm{O})\right.$ $\mathrm{H})=379.93 \pm 1.13 \mathrm{~kJ} \mathrm{~mol}^{-1}$ and $\mathrm{BDE}_{298}(p$ $\left.\mathrm{CH}_{3} \mathrm{C}_{6} \mathrm{H}_{4} \mathrm{C}(\mathrm{O})-\mathrm{H}\right)=379.85 \pm 1.13 \mathrm{~kJ} \mathrm{~mol}^{-1}, \quad$ are indistinguishable (within the uncertainty) from each other and when compared to the BDE in benzaldehyde. However, in ortho-tolualdehyde, the corresponding $\mathrm{BDE}$ is consistently lower essentially by $4.2 \mathrm{~kJ} \mathrm{~mol}^{-1}\left(\mathrm{BDE}_{298}\right.$ (o$\left.\mathrm{CH}_{3} \mathrm{C}_{6} \mathrm{H}_{4} \mathrm{C}(\mathrm{O})-\mathrm{H}\right)=376.09 \pm 1.13 \mathrm{~kJ} \mathrm{~mol}^{-1}$ ), lower by $3.85 \pm 1.00 \mathrm{~kJ} \mathrm{~mol}^{-1}$ than that of meta-tolualdehyde, $3.76 \pm 1.00 \mathrm{~kJ} \mathrm{~mol}^{-1}$ than that in para-tolualdehyde and $4.01 \pm 0.92 \mathrm{~kJ} \mathrm{~mol}^{-1}$ than that in benzaldehyde. Therefore, the likely origin of the reactivity differences is simply due to the bond enthalpies in the abstraction of aldehydic $\mathrm{H}$ atoms. 


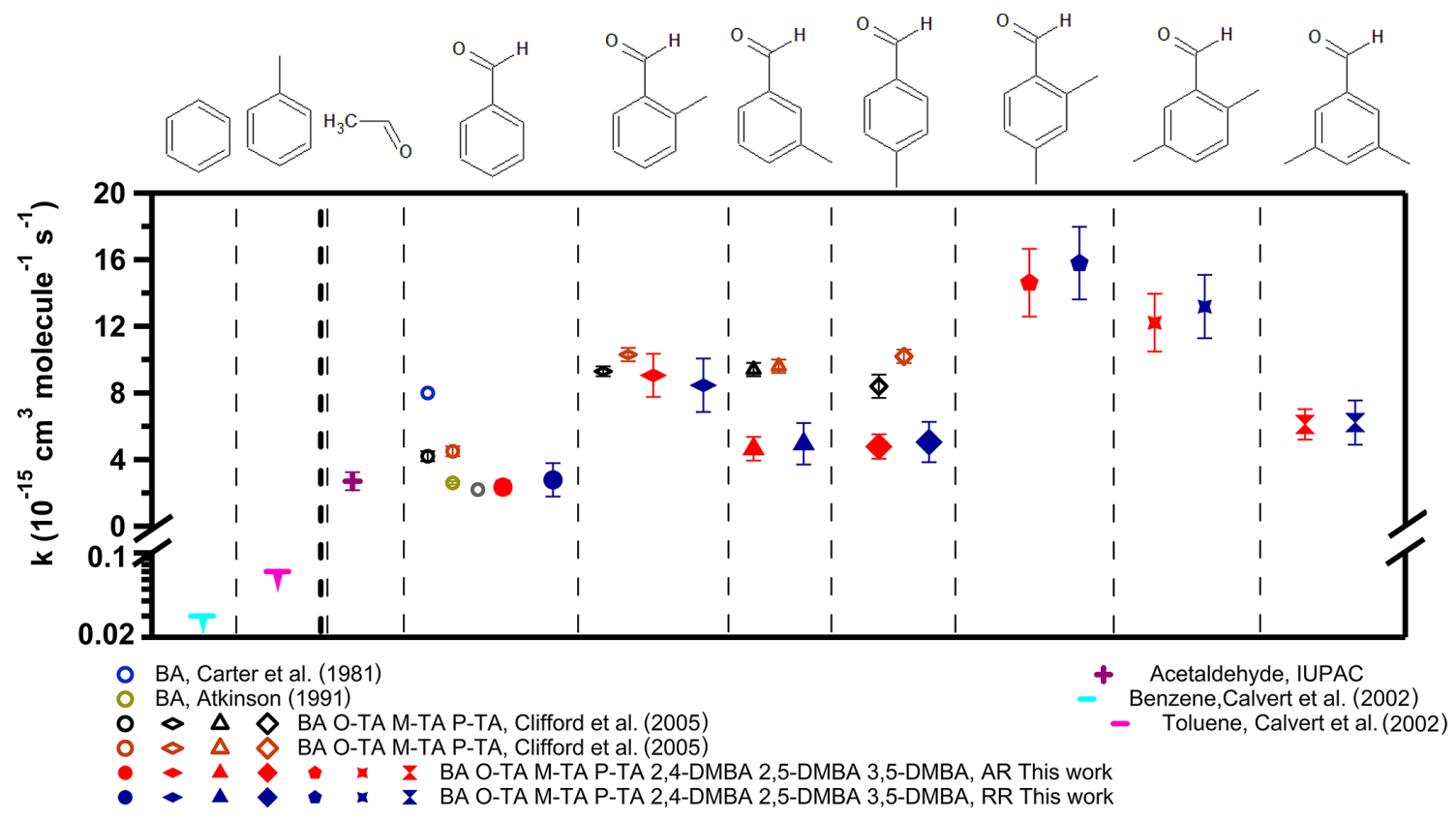

Figure 5. The measured rate coefficients for reactions of the $\mathrm{NO}_{3}$ radical with the seven aldehydes studied here. The results of previously reported rate coefficients are also shown (values are presented in Table 2). The rate coefficient for acetaldehyde of $k_{\left(\mathrm{CH}_{3} \mathrm{CHO}\right)}=(2.7 \pm 0.5) \times$ $10^{-15} \mathrm{~cm}^{3}$ molec. ${ }^{-1} \mathrm{~s}^{-1}$ is from IUPAC recommendations. The rate coefficients for benzene of $k_{(\text {benzene })}<3 \times 10^{-17} \mathrm{~cm}^{3}$ molec. ${ }^{-1} \mathrm{~s}^{-1}$ and for toluene of $k_{\text {(toluene) }} \leq 6.6 \times 10^{-17} \mathrm{~cm}^{3}$ molec. ${ }^{-1} \mathrm{~s}^{-1}$ are from Calvert et al. (2002).

Based on the discussion above, it appears that the preponderance of evidence is consistent with the abstraction of the aldehydic $\mathrm{H}$ atom. However, could such an abstraction reaction start via the addition of $\mathrm{NO}_{3}$ to the ring followed by abstraction? To examine this possibility, we carried out quantum mechanical calculations of the reaction pathways in Reaction (R1). Stationary points on the potential energy surface (PES) were optimized with the BH\&HLYP density functional and 6-311G(d,p) basis set in Gaussian 16 (Becke, 1993; Frisch et al., 2016), except for the $\mathrm{NO}_{3}$ radical, for which the MP2-D3h geometry was used. This level of theory and empirical treatment of $\mathrm{NO}_{3}$ follows Boyd's computational studies with smaller aldehydes, $X \mathrm{CHO}(X=\mathrm{H}$, $\mathrm{F}, \mathrm{Cl}, \mathrm{Me}$ ) (Mora-Diez and Boyd, 2002). Single-point energies were evaluated at the DLPNO-CCSD(T)/cc-pVTZ level of theory with tight SCF convergence and TightPNO cutoffs in Orca (Neese, 2012; Riplinger and Neese, 2013; Riplinger et al., 2013). Relative energetics with this basis set are essentially converged, since the effect of using cc-pVQZ on the activation barrier is less than $1 \mathrm{~kJ} \mathrm{~mol}^{-1}$. The calculated PES is shown in Fig. 6. Computed enthalpic and Gibbs energy changes include unscaled vibrational zero-point energies and translational, rotational and vibrational contributions at 298.15 K (Luchini et al., 2020).

The computed reaction pathways show that the $\mathrm{NO}_{3}$ radical can form a dearomatized $\sigma$ adduct (Fig. 6, LHS). The most stable of these adducts (by more than $10 \mathrm{~kJ} \mathrm{~mol}^{-1}$ ) occurs at the para-position. While this complexation is exother- mic, it is endergonic by $17.0 \mathrm{~kJ} \mathrm{~mol}^{-1}$ due to unfavorable entropic effects, implying this is a readily reversible process. H-atom transfer first forms a pre-reaction complex with the aldehydic group. This complex can undergo H-atom abstraction to yield the stable products observed in our experiments. Application of the Bigeleisen-Mayer equation to this $\mathrm{H}$-atom transfer transition structure (TS) results in a computationally predicted primary KIE of 2.16 (2.17 with Bell's 1D-tunneling correction) (Bigeleisen and Mayer, 1947; Paton, 2016; Rzepa, 2015). This value is almost identical to the measure KIE of 1.92 .

Based on this evidence, we suggest that the reactions of $\mathrm{NO}_{3}$ with aromatic aldehydes lead to the abstraction of the aldehydic $\mathrm{H}$ atom. The cleavage of the aldehydic $\mathrm{C}-\mathrm{H}$ bond in this step is consistent with the observation that a weaker $\mathrm{BDE}$ value is correlated with a larger reaction rate of Reaction (R1). CBS-QB3 calculations (see the Supplement) imply that 2,4-DMBA and 2,5-DMBA, like O-TA, have weaker aldehydic $\mathrm{C}-\mathrm{H}$ bonds than the other aromatic aldehydes that lack an ortho-substituent. Since the geometry of the formyl radical is more linear than the aldehyde (the $\mathrm{C}-\mathrm{C}-\mathrm{O}$ angle increases by around $4^{\circ}$ upon $\mathrm{H}$-atom abstraction), steric strain relief is likely a contributing factor to the $\mathrm{C}-\mathrm{H}$ bond weakening by an ortho-methyl substituent. Additionally, charge transfer of $0.22 \mathrm{e}$ from $\mathrm{BA}$ to $\mathrm{NO}_{3}$ occurs in the computed $\mathrm{H}-$ atom transfer TS, consistent with the observation that additional electron-donating substituents, such as methyl groups, promote Reaction (R1). To sum up, the combination of the 

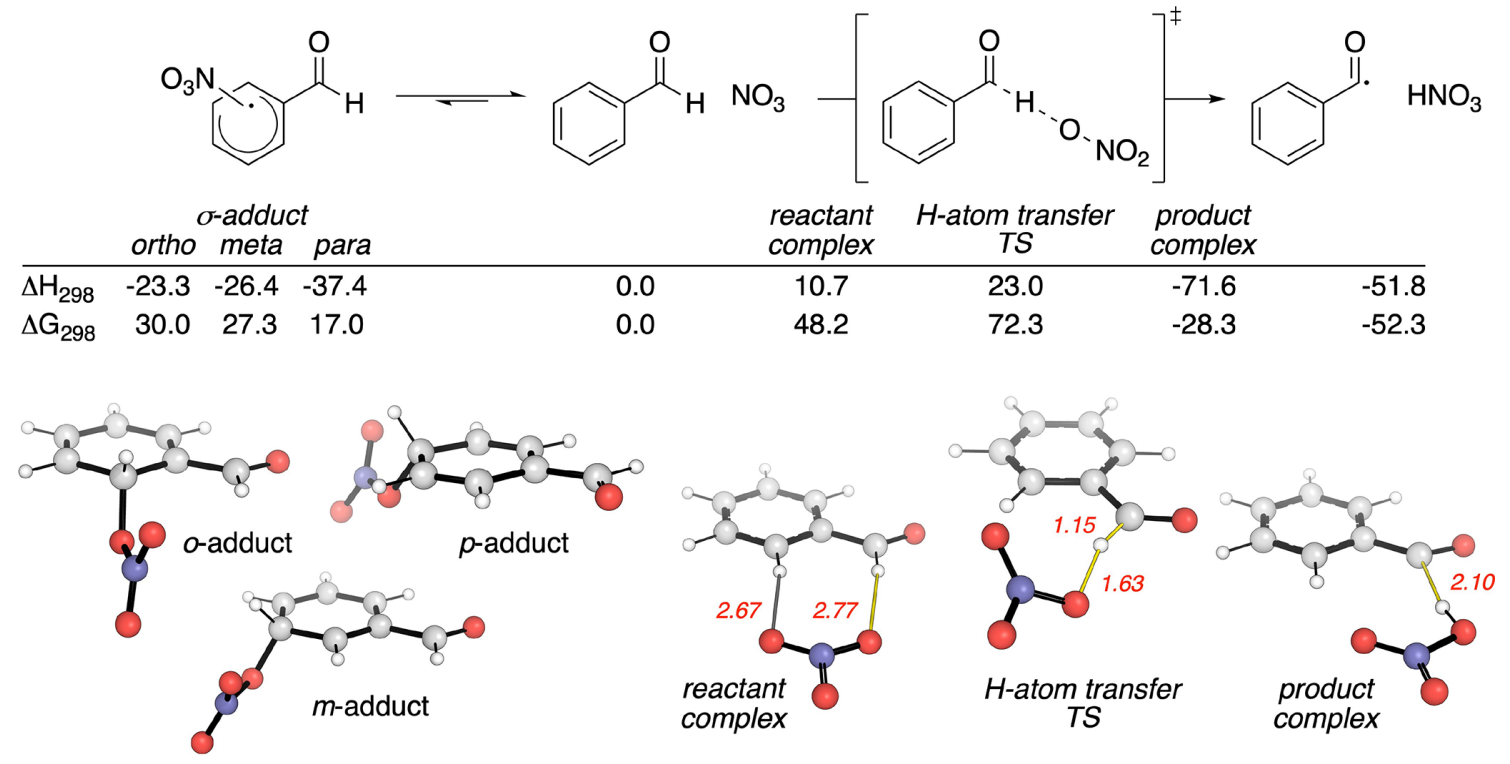

Figure 6. Pathways for the reaction between $\mathrm{BA}$ and $\mathrm{NO}_{3}$ calculated using DLPNO-CCSD(T)/cc-pVTZ//BH\&HLYP/6-311G(d,p). Enthalpic and Gibbs energy values are in kilojoules per mole $\left(\mathrm{kJ} \mathrm{mol}^{-1}\right)$. Key distances are in Ångströms (A).

Table 3. Summary of rate coefficients and estimated atmospheric lifetimes of benzaldehyde (BA), $o$-tolualdehyde (O-TA), $m$ tolualdehyde (M-TA), p-tolualdehyde (P-TA), 2,4-dimethylbenzaldehyde (2,4-DMBA), 2,5-dimethylbenzaldehyde (2,5-DMBA) and 3,5dimethylbenzaldehyde (3,5-DMBA) with respect to their reactions with $\mathrm{OH}, \mathrm{NO}_{3}$ and $\mathrm{Cl}$ at $298 \pm 2 \mathrm{~K}$ and atmospheric pressure. ${ }^{\text {a }}$ For comparison, the rough photolysis lifetimes are also noted for roughly $40^{\circ} \mathrm{N}$ during summer.

\begin{tabular}{|c|c|c|c|c|c|c|c|}
\hline & \multicolumn{4}{|c|}{ Rate coefficients $\left(\mathrm{cm}^{3}\right.$ molec. $\left.{ }^{-1} \mathrm{~s}^{-1}\right)$} & \multicolumn{3}{|c|}{ Lifetime (h) } \\
\hline & $k_{\mathrm{OH}}^{\mathrm{b}}$ & $k_{\mathrm{NO}_{3}}^{\mathrm{c}}$ & $k_{\mathrm{Cl}}^{\mathrm{b}}$ & $\tau_{\mathrm{OH}}$ & $\tau_{\mathrm{NO}_{3}}$ & $\tau_{\mathrm{Cl}}$ & $\tau_{\mathrm{hv}}$ \\
\hline BA & $1.26 \times 10^{-11}$ & $2.6 \times 10^{-15}$ & $9.90 \times 10^{-11}$ & $2.2-22$ & 217 & 281 & $\sim 2$ \\
\hline O-TA & $1.89 \times 10^{-11}$ & $8.7 \times 10^{-15}$ & $1.86 \times 10^{-10}$ & $1.5-15$ & 64 & 149 & $\sim 2$ \\
\hline M-TA & $1.68 \times 10^{-11}$ & $4.9 \times 10^{-15}$ & $1.71 \times 10^{-10}$ & $1.7-17$ & 114 & 162 & $\sim 2$ \\
\hline P-TA & $1.68 \times 10^{-11}$ & $4.9 \times 10^{-15}$ & $1.41 \times 10^{-10}$ & $1.7-17$ & 113 & 197 & $\sim 2$ \\
\hline 2,4-DMBA & $3.12 \times 10^{-11}$ & $1.51 \times 10^{-14}$ & $8.70 \times 10^{-11}$ & $0.9-9$ & 37 & 319 & $<2$ \\
\hline 2,5-DMBA & $3.15 \times 10^{-11}$ & $1.28 \times 10^{-14}$ & $9.30 \times 10^{-11}$ & $0.9-9$ & 43 & 299 & $<2$ \\
\hline 3,5-DMBA & $2.78 \times 10^{-11}$ & $6.2 \times 10^{-15}$ & $9.30 \times 10^{-11}$ & $1-10$ & 89 & 299 & $<2$ \\
\hline
\end{tabular}

${ }^{a}$ We show a range of lifetimes by assuming $[\mathrm{OH}]=1-10 \times 10^{6}$ molec. $\mathrm{cm}^{-3},\left[\mathrm{NO}_{3}\right]=5 \times 10^{8}$ molec. $\mathrm{cm}^{-3}$ (Atkinson et al., 1991) and $[\mathrm{Cl}]=1 \times 10^{4}$ (Wingenter et al., 1996). ${ }^{\mathrm{b}}$ The rate coefficients for the $\mathrm{OH}$ and $\mathrm{Cl}$ atom reactions are from Calvert et al. (2011). ${ }^{\mathrm{C}}$ Recommended values in Table 2.

changes in the $\mathrm{C}-\mathrm{H}$ bond energies and the changes in the variations in the initial addition to form a pre-reaction complex contributed to the observed reactivity trend.

There are potential future experiments that could shed light on the proposed reaction pathway. They include the following: (1) measurement of the temperature dependence of the reaction rate coefficient; (2) investigating the influence of various isotopic substitutions (e.g., OD reaction studies); (3) studying further substitution of the aromatic ring, for example, with fluorine; and (4) directly detecting the radical formed in the reaction. Further quantum calculations may also be useful.

\section{Atmospheric implications}

Once emitted from biomass burning and incomplete fuel burning to the atmosphere, the studied aromatic aldehydes would be removed through photolysis and reactions with reactive species such as $\mathrm{OH}, \mathrm{NO}_{3}$ and chlorine atoms. The atmospheric lifetimes of the aromatic aldehydes studied in this work have been calculated with respect to the $\mathrm{NO}_{3}$ radical reactions using the rate coefficients, $k_{\text {aro }}$, obtained from this work at ambient temperature and pressure, in combination with estimated ambient tropospheric $\mathrm{NO}_{3}$ concentrations of $\left[\mathrm{NO}_{3}\right]=5 \times 10^{8}$ molec. $\mathrm{cm}^{-3}$ (Atkinson, 1991) following the equation $\tau_{\mathrm{NO}_{3}}=1 /\left(k_{\mathrm{VOC}} \times\left[\mathrm{NO}_{3}\right]\right)$. It has been 
pointed out (Brown and Stutz, 2012) that the $\mathrm{NO}_{3}$ radical concentration is highly variable, and we use this value to illustrate the relative loss rates. The calculated lifetimes are shown in Table 3, and they are meant only to compare the loss rates roughly. Actual lifetime needs to be calculated for the location and its condition; it can vary by orders of magnitude from those noted in the table. Based on our measurements, we expect the aromatic aldehyde atmospheric lifetimes with respect to $\mathrm{NO}_{3}$ to be $37-218 \mathrm{~h}$ (for the assumed $\mathrm{NO}_{3}$ concentrations). Table 3 also presents the lifetime of these seven aromatic aldehydes with respect to $\mathrm{OH}$ radicals of $1 \times 10^{6}$ molec. $\mathrm{cm}^{-3}$ (again a rough value characteristic of the mid-tropospheric tropical regions), $\mathrm{Cl}$ atoms (Wingenter et al., 1996) of $1 \times 10^{4}$ atoms $\mathrm{cm}^{-3}$ and the rate coefficients taken from Calvert et al. (2011). It is clear that photolysis dominates, and $\mathrm{OH}$ radicals contribute more than $\mathrm{Cl}$ atoms to oxidation of aromatic aldehydes in the atmosphere during the daytime. Though $\mathrm{NO}_{3}$ reactions contributed much less on a diurnally averaged basis, they are the only pathways for the degradation of these aldehydes at night. The $\mathrm{NO}_{3}$ reactions could contribute significantly to removing aromatic aldehydes at night in polluted areas with high $\mathrm{NO}_{x}$. Various studies have seen large abundances of $\mathrm{NO}_{3}$ radicals. For example, the following $\mathrm{NO}_{3}$ mixing ratios have been reported: Pitts et al. (1984) up to 430 pptv in the eastern Los Angeles Basin, including Riverside; Wang et al. (2006) up to $200 \mathrm{pptv}$ in the Phoenix downtown area; Brown et al. $(2009,2011)$ up to 400 pptv in the Houston urban area; Platt et al. (1981) around 280 pptv at Deuselbach, Germany; and Asaf et al. (2009, 2010) up to $800 \mathrm{pptv}$ around Jerusalem. In addition, the $\mathrm{NO}_{3}$ reactions also could lead to PAN-type compounds at night.

This work also found that the aromatic PAN-type compound, for example, was the main product formed from the reaction of aromatic aldehydes with the $\mathrm{NO}_{3}$ radical. The formation of such compounds enables the transport and release of $\mathrm{NO}_{x}$ to the remote troposphere, leading to the production of $\mathrm{O}_{3}$. Such a situation may occur in wildland fire plumes.

Data availability. The compiled datasets used to produce each figure within this paper are available as Igor Pro files upon request.

Supplement. The supplement related to this article is available online at: https://doi.org/10.5194/acp-21-13537-2021-supplement.

Author contributions. YR and ARR wrote the paper with input from all authors. YR and LZ conducted the experiments and analyzed the data; MM helped with the data analysis. MI, VD and SSB were responsible for the CRDS instrument. BR and RSP made the theoretical calculations. AM and ARR designed the experiments and led the study. All coauthors commented on the paper.
Competing interests. The authors declare that they have no conflict of interest.

Disclaimer. Publisher's note: Copernicus Publications remains neutral with regard to jurisdictional claims in published maps and institutional affiliations.

Special issue statement. This article is part of the special issue "Simulation chambers as tools in atmospheric research (AMT/ACP/GMD inter-journal SI)". It is not associated with a conference.

Acknowledgements. We are grateful to Timothy Wallington for the IR cross sections of BAPAN.

This work is supported by the European Union's Horizon 2020 research and innovation program through the EUROCHAMP-2020 Infrastructure Activity under grant agreement no. 730997, Labex Voltaire (ANR-10-LABX-100-01), ANR (SEA_M project, ANR16-CE01-0013, program ANR-RGC 2016) and the National Natural Science Foundation of China (21976106). The work of BR was supported by the US Department of Energy, Office of Science, Office of Basic Energy Sciences, Division of Chemical Sciences, Geosciences, and Biosciences through the Gas-Phase Chemical Physics Program under contract no. DE-AC02-06CH11357. RSP acknowledges the use of the RMACC Summit supercomputer, which is supported by the National Science Foundation (ACI-1532235 and ACI-1532236), the University of Colorado Boulder and Colorado State University, and the Extreme Science and Engineering Discovery Environment (XSEDE) through allocation TG-CHE180056. Le Studium and CSU supported the work of ARR.

Financial support. This research has been supported by the European Commission Horizon 2020 Framework Programme (grant no. EUROCHAMP-2020 (730997)), the Agence Nationale de la Recherche (grant nos. ANR-10-LABX-100-01 and ANR-16-CE010013), and the National Natural Science Foundation of China (grant no. 21976106).

Review statement. This paper was edited by Jason Surratt and reviewed by three anonymous referees.

\section{References}

Asaf, D., Pedersen, D., Matveev, V., Peleg, M., Kern, C., Zingler, J., Platt, U., and Luria, M.: Long-Term Measurements of $\mathrm{NO}_{3}$ Radical at a Semiarid Urban Site: 1. Extreme Concentration Events and Their Oxidation Capacity, Environ. Sci. Technol., 43, 91179123, https://doi.org/10.1021/es900798b, 2009.

Asaf, D., Tas, E., Pedersen, D., Peleg, M., and Luria, M.: LongTerm Measurements of $\mathrm{NO}_{3}$ Radical at a Semiarid Urban Site: 2 . Seasonal Trends and Loss Mechanisms, Environ. Sci. Technol., 44, 5901-5907, https://doi.org/10.1021/es100967z, 2010. 
Atkinson, R., Aschmann, S. M., Winer, A. M., and Pitts, J. N.: Kinetics of the gas-phase reactions of nitrate radicals with a series of dialkenes, cycloalkenes, and monoterpenes at $295 \pm 1 \mathrm{~K}$, Environ. Sci. Technol., 18, 370-375, https://doi.org/10.1021/es00123a016, 1984.

Atkinson, R.: Kinetics and Mechanisms of the Gas-Phase Reactions of the $\mathrm{NO}_{3}$ Radical with Organic Compounds, J. Phys. Chem. Ref. Data, 20, 459-507, https://doi.org/10.1063/1.555887, 1991.

Becke, A. D.: A new mixing of Hartree-Fock and local density-functional theories, J. Chem. Phys., 98, 1372-1377, https://doi.org/10.1063/1.464304, 1993.

Bigeleisen, J. and Mayer, M. G.: Calculation of Equilibrium Constants for Isotopic Exchange Reactions, J. Chem. Phys., 15, 261267, https://doi.org/10.1063/1.1746492, 1947.

Bossmeyer, J., Brauers, T., Richter, C., Rohrer, F., Wegener, R., and Wahner, A.: Simulation chamber studies on the $\mathrm{NO}_{3}$ chemistry of atmospheric aldehydes, Geophys. Res. Lett., 33, L18810, https://doi.org/10.1029/2006GL026778, 2006.

Brauers, T. and Finlayson-Pitts, B. J.: Analysis of relative rate measurements, Int. J. Chem. Kinet., 29, 665-672, https://doi.org/10.1002/(SICI)1097-4601(1997)29:9<665::AIDKIN3>3.0.CO;2-S, 1997.

Bross, D. H., Yu, H.-G., Harding, L. B., and Ruscic, B.: Active Thermochemical Tables: The Partition Function of Hydroxymethyl $\left(\mathrm{CH}_{2} \mathrm{OH}\right)$ Revisited, J. Phys. Chem. A, 123, 4212-4231, https://doi.org/10.1021/acs.jpca.9b02295, 2019.

Brown, S. S. and Stutz, J.: Nighttime radical observations and chemistry, Chem. Soc. Rev., 41, 6405-6447, https://doi.org/10.1039/C2CS35181A, 2012.

Brown, S. S., Stark, H., Ciciora, S. J., McLaughlin, R. J., and Ravishankara, A. R.: Simultaneous in situ detection of atmospheric $\mathrm{NO}_{3}$ and $\mathrm{N}_{2} \mathrm{O}_{5}$ via cavity ring-down spectroscopy, Rev. Sci. Instrum., 73, 3291-3301, https://doi.org/10.1063/1.1499214, 2002.

Brown, S. S., Dubé, W. P., Fuchs, H., Ryerson, T. B., Wollny, A. G., Brock, C. A., Bahreini, R., Middlebrook, A. M., Neuman, J. A., Atlas, E., Roberts, J. M., Osthoff, H. D., Trainer, M., Fehsenfeld, F. C., and Ravishankara, A. R.: Reactive uptake coefficients for $\mathrm{N}_{2} \mathrm{O}_{5}$ determined from aircraft measurements during the Second Texas Air Quality Study: Comparison to current model parameterizations, J. Geophys. Res.-Atmos., 114, D00F10, https://doi.org/10.1029/2008JD011679, 2009.

Brown, S. S., Dubé, W. P., Peischl, J., Ryerson, T. B., Atlas, E., Warneke, C., de Gouw, J. A., te Lintel Hekkert, S., Brock, C. A., Flocke, F., Trainer, M., Parrish, D. D., Feshenfeld, F. C., and Ravishankara, A. R.: Budgets for nocturnal VOC oxidation by nitrate radicals aloft during the 2006 Texas Air Quality Study, J. Geophys. Res.-Atmos., 116, D24305, https://doi.org/10.1029/2011JD016544, 2011.

Burkholder, J. B., Sander, S. P., Abbatt, J., Barker, J. R., Huie, R. E., Kolb, C. E., Kurylo, M. J., Orkin, V. L., Wilmouth, D. M., and Wine, P. H.: Chemical Kinetics and Photochemical Data for Use in Atmospheric Studies, Evaluation No. 18, in, edited by: JPL Publication 15-10, J. P. L., Pasadena, 2015.

Calvert, J. G., Atkinson, R., Becker, K. H., Kamens, R. M., Seinfeld, J. H., Wallington, T. J., and Yarwood, G.: The Mechanisms of Atmospheric Oxidation of Aromatic Hydrocarbons, Oxford University Press, London, 2002.
Calvert, J. G., Mellouki, A., Orlando, J. J., Pilling, M. J., and Wallington, T. J.: The Mechanisms of Atmospheric Oxidation of the Oxygenates, Oxford University Press, New York, 2011.

Caralp, F., Foucher, V., Lesclaux, R., J. Wallington, T., and Hurley, M. D.: Atmospheric chemistry of benzaldehyde: UV absorption spectrum and reaction kinetics and mechanisms of the $\mathrm{C}_{6} \mathrm{H}_{5} \mathrm{C}(\mathrm{O}) \mathrm{O}_{2}$ radical, Phys. Chem. Chem. Phys., 1, 3509-3517, https://doi.org/10.1039/A903088C, 1999.

Carter, W. P. L., Winer, A. M., and Pitts, J. N.: Major atmospheric sink for phenol and the cresols. Reaction with the nitrate radical, Environ. Sci. Technol., 15, 829-831, https://doi.org/10.1021/es00089a009, 1981.

Clifford, G. M., Thüner, L. P., Wenger, J. C., and Shallcross, D. E.: Kinetics of the gas-phase reactions of $\mathrm{OH}$ and $\mathrm{NO}_{3}$ radicals with aromatic aldehydes, J. Photoch. Photobio. A, 176, 172-182, https://doi.org/10.1016/j.jphotochem.2005.09.022, 2005.

Clifford, G. M., Hadj-Aïssa, A., Healy, R. M., Mellouki, A., Muñoz, A., Wirtz, K., Martín Reviejo, M., Borrás, E., and Wenger, J. C.: The Atmospheric Photolysis of o-Tolualdehyde, Environ. Sci. Technol., 45, 9649-9657, https://doi.org/10.1021/es2026533, 2011.

Curtiss, L. A., Redfern, P. C., Raghavachari, K., and Pople, J. A.: Gaussian-3X (G3X) theory: Use of improved geometries, zeropoint energies, and Hartree-Fock basis sets, J. Chem. Phys., 114, 108-117, https://doi.org/10.1063/1.1321305, 2000.

Curtiss, L. A., Redfern, P. C., and Raghavachari, K.: Gaussian-4 theory, J. Chem. Phys., 126, 084108, https://doi.org/10.1063/1.2436888, 2007.

Dubé, W. P., Brown, S. S., Osthoff, H. D., Nunley, M. R., Ciciora, S. J., Paris, M. W., McLaughlin, R. J., and Ravishankara, A. R.: Aircraft instrument for simultaneous, in situ measurement of $\mathrm{NO}_{3}$ and $\mathrm{N}_{2} \mathrm{O}_{5}$ via pulsed cavity ring-down spectroscopy, Rev. Sci. Instrum., 77, 034101, https://doi.org/10.1063/1.2176058, 2006.

Frisch, M. J., Trucks, G. W., Schlegel, H. B., Scuseria, G. E., Robb, M. A., Cheeseman, J. R., Scalmani, G., Barone, V., Petersson, G. A., Nakatsuji, H., Li, X., Caricato, M., Marenich, A. V., Bloino, J., Janesko, B. G., Gomperts, R., Mennucci, B., Hratchian, H. P., Ortiz, J. V., Izmaylov, A. F., Sonnenberg, J. L., Williams, Ding, F., Lipparini, F., Egidi, F., Goings, J., Peng, B., Petrone, A., Henderson, T., Ranasinghe, D., Zakrzewski, V. G., Gao, J., Rega, N., Zheng, G., Liang, W., Hada, M., Ehara, M., Toyota, K., Fukuda, R., Hasegawa, J., Ishida, M., Nakajima, T., Honda, Y., Kitao, O., Nakai, H., Vreven, T., Throssell, K., Montgomery Jr., J. A., Peralta, J. E., Ogliaro, F., Bearpark, M. J., Heyd, J. J., Brothers, E. N., Kudin, K. N., Staroverov, V. N., Keith, T. A., Kobayashi, R., Normand, J., Raghavachari, K., Rendell, A. P., Burant, J. C., Iyengar, S. S., Tomasi, J., Cossi, M., Millam, J. M., Klene, M., Adamo, C., Cammi, R., Ochterski, J. W., Martin, R. L., Morokuma, K., Farkas, O., Foresman, J. B., and Fox, D. J.: Gaussian 16 Rev. C.01, in: Wallingford, CT, Revision B.01, Gaussian, Inc., 2016.

Koss, A. R., Sekimoto, K., Gilman, J. B., Selimovic, V., Coggon, M. M., Zarzana, K. J., Yuan, B., Lerner, B. M., Brown, S. S., Jimenez, J. L., Krechmer, J., Roberts, J. M., Warneke, C., Yokelson, R. J., and de Gouw, J.: Non-methane organic gas emissions from biomass burning: identification, quantification, and emission factors from PTR-ToF during the FIREX 2016 laboratory experiment, Atmos. Chem. Phys., 18, 3299-3319, https://doi.org/10.5194/acp-18-3299-2018, 2018. 
Legreid, G., Reimann, S., Steinbacher, M., Staehelin, J., Young, D., and Stemmler, K.: Measurements of OVOCs and NMHCs in a Swiss Highway Tunnel for Estimation of Road Transport Emissions, Environ. Sci. Technol., 41, 7060-7066, https://doi.org/10.1021/es062309+, 2007.

Luchini, G., Alegre-Requena, J., Funes-Ardoiz, I., and Paton, R.: GoodVibes: automated thermochemistry for heterogeneous computational chemistry data [version 1; peer review: 2 approved with reservations], F1000Research, 9, https://doi.org/10.12688/f1000research.22758.1, 2020.

Martin, J. M. L. and de Oliveira, G.: Towards standard methods for benchmark quality ab initio thermochemistry - W1 and W2 theory, J. Chem. Phys., 111, 1843-1856, https://doi.org/10.1063/1.479454, 1999.

Montgomery, J. A., Frisch, M. J., Ochterski, J. W., and Petersson, G. A.: A complete basis set model chemistry. VI. Use of density functional geometries and frequencies, J. Chem. Phys., 110, 2822-2827, https://doi.org/10.1063/1.477924, 1999.

Montgomery, J. A., Frisch, M. J., Ochterski, J. W., and Petersson, G. A.: A complete basis set model chemistry. VII. Use of the minimum population localization method, J. Chem. Phys., 112, 6532-6542, https://doi.org/10.1063/1.481224, 2000.

Mora-Diez, N. and Boyd, R. J.: A Computational Study of the Kinetics of the $\mathrm{NO}_{3}$ Hydrogen-Abstraction Reaction from a Series of Aldehydes (XCHO: $\mathrm{X}=\mathrm{F}, \mathrm{Cl}, \mathrm{H}, \mathrm{CH}_{3}$ ), J. Phys. Chem. A, 106, 384-394, https://doi.org/10.1021/jp0125000, 2002.

Neese, F.: The ORCA program system, WIREs Comput. Mol. Sci., 2, 73-78, https://doi.org/10.1002/wcms.81, 2012.

Obermeyer, G., Aschmann, S. M., Atkinson, R., and Arey, J.: Carbonyl atmospheric reaction products of aromatic hydrocarbons in ambient air, Atmos. Environ., 43, 3736-3744, https://doi.org/10.1016/j.atmosenv.2009.04.015, 2009.

Ochterski, J. W., Petersson, G. A., and Montgomery, J. A.: A complete basis set model chemistry. V. Extensions to six or more heavy atoms, J. Chem. Phys., 104, 2598-2619, https://doi.org/10.1063/1.470985, 1996.

Organization for Economic Co-operation and Development (OECD): OECD integrated HPV database, available at: https: //hpvchemicals.oecd.org/UI/Search.aspx (last access: $16 \mathrm{Au}-$ gust 2021), 2002.

Parthiban, S. and Martin, J. M. L.: Assessment of W1 and W2 theories for the computation of electron affinities, ionization potentials, heats of formation, and proton affinities, J. Chem. Phys., 114, 6014-6029, https://doi.org/10.1063/1.1356014, 2001.

Paton, R.: Kinisot: v 1.0.0 public API for Kinisot.py, Zenodo, KINISOT, Zenodo [code], https://doi.org/10.5281/zenodo.60082, 2016.

Pitts, J., Winer, A., Sweetman, J. A., Zielinska, B., and Harger, W.: Particulate and gas-phase mutagens in ambient and simulated atmospheres, Final report (Part 2), contract number A3-049-32, California Air Resources Board, 1984.

Platt, U., Perner, D., Schröder, J., Kessler, C., and Toennissen, A.: The diurnal variation of $\mathrm{NO}_{3}$, J. Geophys. Res.-Oceans, 86, 11965-11970, https://doi.org/10.1029/JC086iC12p11965, 1981.

Platz, J., Nielsen, O. J., Wallington, T. J., Ball, J. C., Hurley, M. D., Straccia, A. M., Schneider, W. F., and Sehested, J.: Atmospheric Chemistry of the Phenoxy Radical, $\mathrm{C}_{6} \mathrm{H}_{5} \mathrm{O}(\cdot)$ : UV Spectrum and Kinetics of Its Reaction with $\mathrm{NO}, \mathrm{NO}_{2}$, and $\mathrm{O}_{2}$, J. Phys. Chem. A, 102, 7964-7974, https://doi.org/10.1021/jp9822211, 1998.
Riplinger, C. and Neese, F.: An efficient and near linear scaling pair natural orbital based local coupled cluster method, J. Chem. Phys., 138, 034106, https://doi.org/10.1063/1.4773581, 2013.

Riplinger, C., Sandhoefer, B., Hansen, A., and Neese, F.: Natural triple excitations in local coupled cluster calculations with pair natural orbitals, J. Chem. Phys., 139, 134101, https://doi.org/10.1063/1.4821834, 2013.

Ruscic, B. and Bross, D. H.: Thermochemistry, in: Computer Aided Chemical Engineering, edited by: Faravelli, T., Manenti, F., and Ranzi, E., Elsevier, Amsterdam, Netherlands, 3-114, https://doi.org/10.1016/B978-0-444-64087-1.00001-2, 2019.

Ruscic, B. and Bross, D. H.: Active Thermochemical Tables (ATcT) values based on ver. $1.122 p$ of the Thermochemical Network, available at: https://atct.anl.gov/ (last access: 31 March 2021), 2020.

Ruscic, B., Pinzon, R. E., Morton, M. L., von Laszevski, G., Bittner, S. J., Nijsure, S. G., Amin, K. A., Minkoff, M., and Wagner, A. F.: Introduction to Active Thermochemical Tables: Several "Key" Enthalpies of Formation Revisited, J. Phys. Chem. A, 108, 99799997, https://doi.org/10.1021/jp047912y, 2004.

Ruscic, B., Pinzon, R. E., von Laszewski, G., Kodeboyina, D., Burcat, A., Leahy, D., Montoy, D., and Wagner, A. F.: Active Thermochemical Tables: thermochemistry for the 21st century, J. Phys.-Conf. Ser., 16, 561-570, https://doi.org/10.1088/17426596/16/1/078, 2005.

Ruscic, B.: Uncertainty quantification in thermochemistry, benchmarking electronic structure computations, and Active Thermochemical Tables, Int. J. Quantum Chem., 114, 1097-1101, https://doi.org/10.1002/qua.24605, 2014.

Rzepa, H. S.: KINISOT. A basic program to calculate kinetic isotope effects using normal coordinate analysis of transition state and reactants., KINISOT, Zenodo [code], https://doi.org/10.5281/zenodo.19272, 2015.

Wang, S., Ackermann, R., and Stutz, J.: Vertical profiles of $\mathrm{O}_{3}$ and $\mathrm{NO}_{\mathrm{x}}$ chemistry in the polluted nocturnal boundary layer in Phoenix, AZ: I. Field observations by long-path DOAS, Atmos. Chem. Phys., 6, 2671-2693, https://doi.org/10.5194/acp-6-26712006, 2006.

Wayne, R. P.: Chemistry of Atmospheres: An Introduction to the Chemistry of the Atmospheres of Earth, the Planets, and their Satellites, 3 (28 December 2000) ed., Oxford University Press, Oxford, 2000.

Wayne, R. P., Barnes, I., Biggs, P., Burrows, J. P., Canosamas, C. E., Hjorth, J., Lebras, G., Moortgat, G. K., Perner, D., Poulet, G., Restelli, G., and Sidebottom, H.: The nitrate radical - Physics, Chemistry, and the Atmosphere, Atmos. Environ. A-Gen., 25, 1203, https://doi.org/10.1016/0960-1686(91)90192-a, 1991.

Wingenter, O. W., Kubo, M. K., Blake, N. J., Smith, T. W., Blake, D. R., and Rowland, F. S.: Hydrocarbon and halocarbon measurements as photochemical and dynamical indicators of atmospheric hydroxyl, atomic chlorine, and vertical mixing obtained during Lagrangian flights, J. Geophys. Res.-Atmos., 101, 43314340, https://doi.org/10.1029/95JD02457, 1996.

Zaleski, D. P., Sivaramakrishnan, R., Weller, H. R., Seifert, N. A., Bross, D. H., Ruscic, B., Moore III, K. B., Elliott, S. N., Copan, A. V., Harding, L. B., Klippenstein, S. J., and Field, R., and Kirill, P.: Substitution reactions in the pyrolysis of acetone revealed through a modeling, experiment, the- 
ory (MET) paradigm, J. Am. Chem. Soc., 143, 3124-3142, https://doi.org/10.1021/jacs.0c11677, 2021.

Zhou, L., Ravishankara, A. R., Brown, S. S., Idir, M., Zarzana, K. J., Daële, V., and Mellouki, A.: Kinetics of the Reactions of $\mathrm{NO}_{3}$ Radical with Methacrylate Esters, J. Phys. Chem. A, 121, 44644474, https://doi.org/10.1021/acs.jpca.7b02332, 2017.
Zhou, L., Ravishankara, A. R., Brown, S. S., Zarzana, K. J., Idir, M., Daële, V., and Mellouki, A.: Kinetics of the reactions of $\mathrm{NO}_{3}$ radical with alkanes, Phys. Chem. Chem. Phys., 21, 4246-4257, https://doi.org/10.1039/C8CP07675H, 2019. 